This peer-reviewed published paper appears as: Hwang, S-H., Lignos, D.G. (2017). “Assessment of Structural Damage Detection Methods for Steel Structures Using Full-Scale Experimental Data and Nonlinear Analysis, Bulletin of Earthquake Engineering, https://doi.ong/10.1007/s10518-017-0288-2 (in-press).

\title{
Assessment of structural damage detection methods for steel structures using full-scale experimental data and nonlinear analysis
}

\author{
Seong-Hoon Hwang a and Dimitrios G. Lignos ${ }^{\text {a, }}$ \\ ${ }^{a}$ Department of Architecture, Civil and Environmental Engineering, Swiss Federal Institute of Technology, Lausanne (EPFL), \\ Switzerland
}

\begin{abstract}
Rapid structural damage assessment methodologies are essential to properly allocate emergency response and minimize business interruption due to downtime in the aftermath of earthquakes. Within this context, data-driven algorithms supported by sensing capabilities can be potentially employed. In this paper, we evaluate an extensive number of damage indicators computed based on nonmodel-based system identification techniques and wavelet analysis. The efficiency of these indicators to infer the damage state of conventional steel moment-resisting frames (MRFs) and concentrically braced frames (CBFs) is evaluated through the utilization of landmark full-scale shake table experiments that examined the inelastic behavior of such frames at various seismic intensities. The same data is complemented with numerical simulations of multi-story steel MRFs and CBFs with the overarching goal to identify potential limitations and propose refinements in commonly used damage indicators for rapid seismic risk assessment. It is shown that wavelet-based damage sensitive features are well correlated with commonly used story-based engineering demand parameters that control structural and non-structural damage in conventional steel frame buildings.
\end{abstract}

KEY WORDS: structural health monitoring; shake table tests; damage indicators; wavelet analysis; frequency domain decomposition; numerical algorithm for subspace system identification; higher mode effects.

\section{INTRODUCTION}

In the context of earthquake risk management, cities in earthquake prone regions should have the ability to "respond" fast in the aftermath of an earthquake (Bruneau et al. 2003). Therefore, simulation tools are needed to infer the damage state of a structure. Conventional damage assessment techniques typically require the explicit utilization of sophisticated nonlinear model representations of structures, followed by detailed engineering inspections (Tremblay et al.1996; Uang et al.1997; Mahin 1998). Therefore, a considerable time investment is inevitable. Detailed knowledge of the building geometry and material properties is also necessary. To this end, the development, refinement and utilization of nonmodel-based damage diagnosis approaches is emerging.

A number of structural health monitoring (SHM) techniques for damage diagnosis exist. Structural damage is typically inferred based on changes in basic dynamic structural properties [e.g., natural frequency, damping ratio, mode shape(s)] (i.e., vibration-based methods) (Lynch et al. 2016). These changes are either traced in time or frequency domain (Rodgers and Çelebi 2006; Ji et al. 2011; Moaveni et al. 2011; Kim and Lynch 2012; Chang and Pakzad 2013; Ikeda 2016).

Most of the aforementioned techniques have been historically validated with idealized scale models of structures in which damage was induced with a sudden loss of stiffness or strength. A well-known example is the benchmark study that was conducted by the International Association for Structural Control (IASC)-ASCE (Johnson 2004) and provided

\footnotetext{
*Dimitrios G. Lignos (Corresponding author)

Dept. of Architecture, Civil and Environmental Engineering, Swiss Federal Institute of Technology, Lausanne (EPFL), CH1015, Switzerland

Tel.: +41 (0) 216932427

Fax: +41 (0) 216932868

E-mail: dimitrios.lignos@epfl.ch
} 
This peer-reviewed published paper appears as: Hwang, S-H., Lignos, D.G. (2017). “Assessment of Structural Damage Detection Methods for Steel Structures Using Full-Scale Experimental Data and Nonlinear Analysis, Bulletin of Earthquake Engineering, https://doi.ong/10.1007/s10518-017-0288-2 (in-press). insights into several SHM techniques (Bernal and Gunes 2004; Caicedo et al. 2004; Hera and Hou 2004; Luş et al. 2004; Yuen et al. 2004). However, due to the similitude and the way that damage was introduced (i.e., either removal/re-installation of brace members or looseness of bolts) it is quite challenging to relate a number of the findings to the actual inelastic response of capacity-designed structures in which the damage progression follows a certain failure mode hierarchy that does not typically involve premature failures. This is confirmed by several shake table tests conducted in recent years in more realistic scales (Ozcelik et al. 2008; Suita et al. 2008; Ji et al. 2011, Lignos et al. 2011; Okazaki et al. 2013a) as well as past reconnaissance reports (Okazaki et al 2013b; MacRae et al. 2015). In that respect, the role of landmark data from large-scale shake table tests becomes important to further challenge the validity of SHM techniques and highlight potential limitations and future challenges in their further implementation (Nakashima et al. 2010). Few attempts have been made in this direction (Pakzad and Fenves 2009; Saito and Beck 2010; Ji et al. 2011; Moaveni et al. 2011; Chang and Pakzad 2013; Ikeda 2016). In particular, Saito and Beck (2010) proposed a Bayesian framework for model order selection of autoregressive with exogenous term (ARX) (Pakzad and Fenves 2009) for system identification of an instrumented high-rise building in Tokyo. This study suggested that although the building experienced 43 earthquakes over a period of 9 years no significant change in the natural frequencies of the building was observed. In a more recent study, Ikeda (2016) evaluated a system identification method by utilizing shake table test data of a full-scale 4-story steel frame building tested through collapse (Suita $e t$ al. 2008). When the building was damaged, its natural frequencies decreased whereas the damping coefficients increased. In a recent study, Ji et al. (2011) utilized test data from a 4-story steel frame building that was tested at fullscale on the E-Defense shake table. They illustrated that the building's natural frequencies decreased by less than $12 \%$ even when beam local buckling and connection fractures occurred. According to the same study, changes in the dynamic characteristics of the building can hardly trace the geometric location and severity of structural component damage. Typically, localized damage detection requires a high density of instrumentation (Labuz et al. 2010; Li et al. 2017). This increases the labor cost of installation and operation as well as the computation cost to handle the large volume of sensor data (Chang and Pakzad 2014b).

Recent studies (Nair and Kiremidjian 2007; Cruz and Salgado 2009; Noh et al. 2011, 2012; Solís et al. 2013) have utilized signal processing techniques in which the wavelet transform (Mallat 1999) is employed to infer the structural damage state at a given seismic intensity. However, one of the main challenges for their further deployment for earthquake risk assessment is how to establish a relationship between the changes of structural vibration characteristics due to structural damage and typical story-based engineering demand parameters (EDPs).

This paper has two main objectives. It first focuses on the evaluation of a wealth of damage identification techniques for capacity-designed steel frame buildings with either steel moment-resisting frames (MRFs) or concentrically braced frames (CBFs). Several damage indicators derived from frequency- and time-domain algorithms as well as wavelet transformations are considered for this purpose. The evaluation is conducted on the basis of (a) unique full-scale shake table test data conducted at the world's largest shake table at E-Defense in Japan; and (b) virtual data from computer simulations based on state-of-the-art nonlinear building models that capture cyclic and in-cycle strength and stiffness deterioration. The aim is to develop recommendations on the use and limitations of these indicators for earthquakeinduced damage identification of conventional steel lateral load-resisting systems. A refined wavelet-based damage sensitive feature is also proposed that can be utilized in steel frame buildings influenced by higher mode effects. Finally, a relationship between the damage indicators and characteristic story-based EDPs is established at a given seismic intensity. This relationship can facilitate the earthquake-induced risk assessment of steel frame buildings in the context of performance-based earthquake engineering.

\section{REVIEW OF COMMON DAMAGE IDENTIFICATION TECHNIQUES}

In classical system identification techniques, structural damage is typically identified based on measured changes in the structure's basic dynamic properties (e.g., natural frequencies, mode shapes and damping ratios) traced in frequency- and/or time-domain. To this end, three system identification algorithms are considered in the context of 
This peer-reviewed published paper appears as: Hwang, S-H., Lignos, D.G. (2017). “Assessment of Structural Damage Detection Methods for Steel Structures Using Full-Scale Experimental Data and Nonlinear Analysis, Bulletin of Earthquake Engineering, https://doi.ong/10.1007/s10518-017-0288-2 (in-press).

this paper. The first one is the frequency domain decomposition (FDD), which is an output-only version of the conventional complex mode indicator function (CMIF) as discussed in Shih et al. (1988) and Peeters and Ventura (2003). This algorithm is based on singular value decomposition (SVD) methods applied to multiple reference frequency response function (FRF) system identification algorithms (Shih et al. 1988; Brincker et al. 2001; Peeters and Ventura 2003); the second one is the autoregressive (AR) with exogenous term (ARX) method, which provides parametric estimates of vibration modes from acceleration response data in the time domain (Pakzad and Fenves 2009); the third one is the numerical algorithm for subspace system identification (N4SID) (Overschee and Moor 1994) to estimate a state-space model as a set of input, output and state variables using a subspace method to estimate a statespace model directly from an arbitrary set of input and output matrices. This provides the physical parameters of the system in the time domain. Extensive studies on the capabilities of other output-only system identification techniques can be found in Moaveni et al. (2011) and Chang and Pakzad (2014a).

Wavelet-based approaches (Hera and Hou 2004; Nair and Kiremidjian 2009; Noh et al. 2011, 2012 ; Aguirre et al. 2013; Balafas and Kiremidjian 2015) that are based on recent advancements in signal processing can be utilized to characterize the extent of the observed structural damage. This is typically achieved by monitoring the changes of damage sensitive features extracted from wavelet analysis. The basis of the four damage identification techniques is briefly described in the subsequent sections.

\subsection{Frequency domain decomposition method}

The FDD method is an output-only system identification technique that is typically used when response data is only available (Brincker et al. 2001). The mathematical relationship between the input excitation, $x(t)$ and the output responses, $y(t)$ is defined as follows,

$$
\mathbf{S}_{y y}(\omega)=\mathbf{H}(\omega) \mathbf{S}_{x x}(\omega) \mathbf{H}^{H}(\omega)
$$

in which $\mathbf{S}_{x x}$ is the power spectral density (PSD) matrix of the input excitation, $x(t)$; $\mathbf{S}_{y y}$ is the PSD matrix of the output response; $\mathbf{H}$ is the frequency response function matrix; and $\mathbf{H}^{H}$ is the complex transpose conjugate of $\mathbf{H}$. When applying the singular value decomposition method to Eq. (1), the output PSD matrix can be decomposed. The standard assumption for the development of the FDD method is that the input excitation $x(t)$ is ideally a white noise and stationary. At known natural frequencies, the building's mode shapes can be identified based on the singular vectors. Therefore, this method can be utilized for structural damage detection by monitoring the changes in these properties relative to the dynamic properties of the undamaged state. More details regarding the theoretical background of the FDD method can be found in Brincker et al. (2001).

\subsection{Autoregressive with exogenous term method}

The ARX method uses least squares to estimate the dynamic properties of a multi-degree-of-freedom (MDF) system from recorded absolute acceleration data in the discrete time domain. This model is mathematically defined as follows,

$$
\sum_{i=0}^{M} \mathbf{A}_{i} \mathbf{y}(n-i)=\sum_{i=0}^{M} \mathbf{B}_{i} \mathbf{x}(n-i)+\mathbf{e}(n)
$$

in which $M$ is the model order of the ARX model; $\mathbf{x}(n)$ and $\mathbf{y}(n)$ are the $p$-dimensional input and $q$-dimensional output vectors, respectively; $\mathbf{e}(n)$ is the residue error vector; and $\mathbf{A}_{i}$ and $\mathbf{B}_{i}$ are the $p \times p$ and $q \times p$ coefficient matrices of the autoregressive (AR) polynomial and exogenous (X) input. The model in Eq. (2) may be re-written as follows,

$$
\mathbf{y}(n)=-\sum_{i=1}^{M} \mathbf{A}_{i} \mathbf{y}(n-i)+\sum_{i=0}^{M} \mathbf{B}_{i} \mathbf{x}(n-i)+\mathbf{e}(n)=\boldsymbol{\Phi}^{T}(n) \cdot \boldsymbol{\Theta}+\mathbf{e}(n)
$$

in which

$$
\boldsymbol{\Phi}^{T}(n)=\left[\begin{array}{llll}
-\mathbf{y}(n-1) & -\mathbf{y}(n-M) & \mathbf{x}(n-1) & \mathbf{x}(n-M)
\end{array}\right]
$$


This peer-reviewed published paper appears as: Hwang, S-H., Lignos, D.G. (2017). “Assessment of Structural Damage Detection Methods for Steel Structures Using Full-Scale Experimental Data and Nonlinear Analysis, Bulletin of Earthquake Engineering, https://doi.ong/10.1007/s10518-017-0288-2 (in-press).

$$
\boldsymbol{\Theta}=\left[\begin{array}{llll}
\mathbf{A} & \mathbf{A}_{M} & \mathbf{B}_{1} & \mathbf{B}_{M}
\end{array}\right]^{\mathrm{T}}
$$

The parameter matrix, $\Theta$ can be estimated based on the least square method as follows,

$$
\arg \min _{\boldsymbol{\Theta}} J(\boldsymbol{\Theta})=\arg \min _{\boldsymbol{\Theta}}\left\|\mathbf{y}(n)-\boldsymbol{\Phi}^{T}(n) \cdot \boldsymbol{\Theta}\right\|^{2}
$$

The AR coefficient and $\mathrm{X}$ input matrices are used to formulate the system matrix of equations. The dynamic properties of a MDF system are estimated by eigenvalue decomposition of the system matrix (Pakzad and Fenves 2009). Due to random noise, it is common that spurious modes are induced. In this case, a stable mode is estimated by changing the order of the ARX model. A stabilization diagram (Pakzad and Fenves 2009; Ji et al. 2011) is typically used for this purpose. From this diagram, stabilization occurs when the relative differences of the dynamic properties identified using two different model orders are within $5 \%, 10 \%$, and $5 \%$ for the natural frequencies, the damping ratios, and the modal assurance criterion (MAC) of the mode shapes (Chang and Pakzad 2013), respectively.

\subsection{Numerical algorithm for subspace system identification method}

The N4SID method is an identification technique to estimate an $n$ th-order state-space model using input/output data as discussed in Kim and Lynch (2012). The mathematical form of N4SID is briefly introduced as follows,

$$
\begin{aligned}
\mathbf{x}_{k+1} & =\mathbf{A} \mathbf{x}_{k}+\mathbf{B} \mathbf{u}_{k}+\mathbf{w}_{k} \\
\mathbf{y}_{k+1} & =\mathbf{C} \mathbf{x}_{k}+\mathbf{D} \mathbf{u}_{k}+\mathbf{v}_{k}
\end{aligned}
$$

in which $\mathbf{A} \in \Re^{n \times n}, \mathbf{B} \in \mathfrak{R}^{n \times m}, \mathbf{C} \in \mathfrak{R}^{l \times n}$, and $\mathbf{D} \in \mathfrak{R}^{l \times m}$ are state-space matrices; $\mathbf{u}_{k} \in \Re^{m \times 1}$ is a vector of $m$ measured inputs at time step $k, \mathbf{y}_{k} \in \Re^{l \times 1}$ is a vector of output at time step $k$ and $\mathbf{x}_{k} \in \Re^{n \times 1}$ is $n$-dimensional unknown discrete state vector; $\mathbf{w}_{\boldsymbol{k}} \in \mathfrak{R}^{n \times 1}$ and $\mathbf{v}_{\boldsymbol{k}} \in \mathfrak{R}^{l \times 1}$ are Gaussian distributed with zero-mean, white noise vector sequences. The covariance matrices of $\mathbf{w}_{k}$ and $\mathbf{v}_{k}$ are defined as follows,

$$
E\left[\left(\begin{array}{c}
\mathbf{w}_{k} \\
\mathbf{v}_{k}
\end{array}\right)\left(\begin{array}{ll}
\mathbf{w}_{q}^{T} & \mathbf{v}_{q}^{T}
\end{array}\right)\right]=\left[\begin{array}{cc}
\mathbf{Q} & \mathbf{S} \\
\mathbf{S}^{T} & \mathbf{R}
\end{array}\right] \delta_{k q}
$$

in which $\mathbf{Q} \in \mathfrak{R}^{n \times n}, \mathbf{S} \in \mathfrak{R}^{n \times l}$ and $\mathbf{R} \in \mathfrak{R}^{l \times l}$. By assuming a linear system, the state and output in Eq. (7) are split up in a deterministic and a stochastic component as follows,

$$
\begin{aligned}
\mathbf{x}_{k+1}^{d} & =\mathbf{A} \mathbf{x}_{k}^{d}+\mathbf{B} \mathbf{u}_{k}, \mathbf{y}_{k}^{d}=\mathbf{C} \mathbf{x}_{k}^{d}+\mathbf{D} \mathbf{u}_{k} \\
\mathbf{x}_{k+1}^{s} & =\mathbf{A} \mathbf{x}_{k}^{s}+\mathbf{w}_{k}, \quad \mathbf{y}_{k}^{s}=\mathbf{C} \mathbf{x}_{k}^{s}+\mathbf{v}_{k}
\end{aligned}
$$

When the stochastic state process $\mathbf{x}_{\boldsymbol{k}}^{\boldsymbol{s}}$ is stationary, the state covariance matrix $\Sigma$ can be defined as follows,

$$
\sum=E\left[\mathbf{x}_{k}^{s}\left(\mathbf{x}_{k}^{s}\right)^{T}\right]=\mathbf{A} \sum \mathbf{A}^{T}+\mathbf{Q} \in \mathfrak{R}^{n \times n}
$$

The problem statement for the identification of a linear-invariance system can be stated as optimal estimation of $\mathbf{A}$, $\mathbf{B}, \mathbf{C}, \mathbf{D}, \mathbf{Q}, \mathbf{R}$ and $\mathbf{S}$ given the measured input sequence (i.e., $\left.\mathbf{u}_{0}, \mathbf{u}_{1}, \ldots, \mathbf{u}_{N-1}\right)$ and output sequence (i.e., $\mathbf{y}_{0}, \mathbf{y}_{1}, \ldots, \mathbf{y}_{N-}$ ${ }_{1}$ ) as $N \rightarrow \infty$ by using numerical methods such as the QR factorization (Overschee and Moor 1994). Once the mathematical description of the state-space model is constructed, dynamic properties can be determined based on eigenvalue decomposition. More details about the mathematical formulation of the N4SID method and its application to various structures can be found in Overschee and Moor (1994) and Kim and Lynch (2012).

\subsection{Wavelet-based damage sensitive features}

In recent years, wavelet-based methods have been proposed for the structural damage identification [e.g., Hera and Hou (2004); Nair and Kiremidjian (2009); Noh et al. (2011, 2012); Aguirre et al. (2013); Balafas and Kiremidjian (2015)]. Given a scale parameter $a>0$, and a time shift parameter $b$, the continuous wavelet transform can be mathematically described as follows,

$$
C(a, b)=\int_{-\infty}^{\infty} f(t) \frac{1}{\sqrt{a}} \psi^{*}\left(\frac{t-b}{a}\right) \mathrm{d} t
$$


This peer-reviewed published paper appears as: Hwang, S-H., Lignos, D.G. (2017). “Assessment of Structural Damage Detection Methods for Steel Structures Using Full-Scale Experimental Data and Nonlinear Analysis, Bulletin of Earthquake Engineering, https://doi.ong/10.1007/s10518-017-0288-2 (in-press). in which $f(t)$ is response history data; $\psi(t)$ is the mother wavelet function (in this paper, Morlet wavelet basis function (Morlet et al. 1982) is used as a mother wavelet); and * is the complex conjugate. A set of basis functions, which are termed as daughter wavelets, is established by continuously dilating and translating the mother wavelet function, $\psi(t)$. The continuous wavelet transform coefficients, $C(a, b)$ are then obtained by convoluting basis functions (i.e., Morlet wavelet basis functions (Morlet et al. 1982)) and response history data, $f(t)$ (e.g., recorded absolute acceleration response history at the building roof). Noh et al. $(2011,2012)$ introduced the damage-sensitive features (DSFs) based on a continuous wavelet transform algorithm. The mathematical form of the wavelet-based DSFs is defined as follows,

$$
D S F=1-\frac{E_{\text {scale }(\hat{a})}}{E_{\text {tot }}}
$$

in which, $E_{\text {scale }(\hat{)})}$ is the wavelet energy at scale $\hat{a}$ over time as defined in Nair and Kiremidjian (2007). This energy can be computed as follows,

$$
E_{\text {scale }(\hat{a})}=\sum_{b=1}^{K}|C(\hat{a}, b \times \Delta t)|^{2}
$$

Referring to Eq. (12), the total wavelet energy, $E_{\text {tot }}$ of the acceleration response data is the sum of the wavelet energies over time at the pre-defined scales. In this paper, two different methods for the computation of the total wavelet energy, $E_{\text {tot }}$ are used: (i) the first one was proposed in Noh et al. (2011). In this case, $E_{\text {tot }}$ is the sum of the wavelet energies over time at scales at $\hat{a}$ and $2 \hat{a}$ that correspond to the first and half of the first natural frequency of the building under consideration, respectively (i.e., $\hat{a}$ is the scale when pseudo-frequency of the daughter wavelet is equivalent to the first natural frequency of undamaged state). Hereafter wavelet-based DSF computed based on this normalization method is noted as $\mathrm{DSF}_{1}$; and (ii) the second one was also proposed by Noh et al. (2012) in a later study. In this case, $E_{\text {tot }}$ is defined as the sum of the wavelet energy of response history data, $f(t)$ at all dyadic scales as follows,

$$
E_{\mathrm{tot}}=\sum_{j=M}^{N} E_{\text {scale }\left(a^{j}\right)}
$$

in which $M$ and $N$ are the minimum and maximum dyadic scales, respectively, determined such that,

$$
\frac{\omega_{0}}{2 \pi\left(2^{M}\right)} \leq \frac{1}{2} f_{s}
$$

$$
2^{N} \leq \frac{\text { Length of data }}{\text { Effective length of wavelet }}
$$

in which $\omega_{0}$ is the coefficient of the Morlet wavelet; and $f_{s}$ is the sampling rate of data. The chosen $\omega_{0}$ is 5 and the effective length of wavelet is 8 in this case. Hereafter the wavelet-based DSF determined based on this normalization method is noted as $\mathrm{DSF}_{2}$. Both wavelet-based DSF values range between 0 (representing no structural damage) and 1 (representing severe structural damage). The question of interest is what the range of corresponding story-based EDPs is such that can be mapped to representative normalized DSF values. This issue as well as pros and cons of using DSF 1 over $\mathrm{DSF}_{2}$ is elaborated in Section 4.3.

\section{DESCRIPTION OF SHAKE TABLE EXPERIMENTS \& NONLINEAR BUILDING MODELS}

To validate the efficiency of commonly used SHM damage identification techniques discussed in Section 2, experimental data from two representative shake table experiments are utilized. One of the test structures employs steel MRFs designed according to today's code provisions (AIJ 2007; AISC 2010b). The second one employs a codecompliant CBF (Lehman et al. 2008; AISC 2010b). The progression of structural damage observed in the test structures is well documented during the tests (e.g., formation and extent of flexural hinging in steel beams and columns, steel brace flexural buckling and fracture) and reflects the damage progression that capacity-designed structures experience during an earthquake. Furthermore, the progression of structural damage is well correlated with story-based EDPs such as peak story drift ratios (SDRs), peak absolute floor accelerations (PFAs) and residual SDRs. In order to investigate 
This peer-reviewed published paper appears as: Hwang, S-H., Lignos, D.G. (2017). “Assessment of Structural Damage Detection Methods for Steel Structures Using Full-Scale Experimental Data and Nonlinear Analysis, Bulletin of Earthquake Engineering, https://doi.ong/10.1007/s10518-017-0288-2 (in-press). the efficiency of the SHM techniques discussed in Section 2 in predicting structural damage in cases that higher mode effects may strongly influence the structural response, the shake table test data are complemented with simulation results from a nonlinear building model of an 8-story steel frame building with MRFs. The efficiency of the employed SHM techniques in predicting the redistribution of forces after the occurrence of structural damage in steel CBFs is further assessed with a nonlinear building model of a 3 -story steel frame building with CBFs. The subsequent sections provide a brief description of each case study structure.

\subsection{Full-scale 4-story steel frame building with MRFs tested through collapse}

Suita et al. (2008) conducted a full-scale shake table experiment that investigated the dynamic response of a 4-story steel frame building with MRFs [see Figure 1(a)] through collapse. The tests were conducted at E-Defense in Japan. The test structure was designed and constructed in accordance with the current Japanese practice (AIJ 2007). The influence of the composite beam effects, autoclaved lightweight aerated concrete (ALC) external wall cladding panels, gypsum board partition walls and hanging ceiling system on the lateral resistance of the system were considered. Figures 1(a) and 1(b) show the test structure on the shake table and its plan and elevation view. The test structure was subjected to a 3-dimensional (3-D) shaking sequence based on the $20 \%, 40 \%, 60 \%$ and $100 \%$ intensities of the unscaled JR Takatori record from the 1995 Hyogo-Ken Nanbu (Kobe) earthquake. The 4-story building collapsed with a firststory mechanism after almost 7 seconds of ground motion shaking during the $100 \%$ JR Takatori record. Once the building fully lost its lateral load resistance (i.e., dynamic instability occurred) it rested on a rigid frame that its purpose was to protect the shake table [see Figure 1(a)]. The seismic performance of the test structure from the onset of damage through structural collapse is well documented in prior studies (Suita et al. 2008; Lignos et al. 2013).

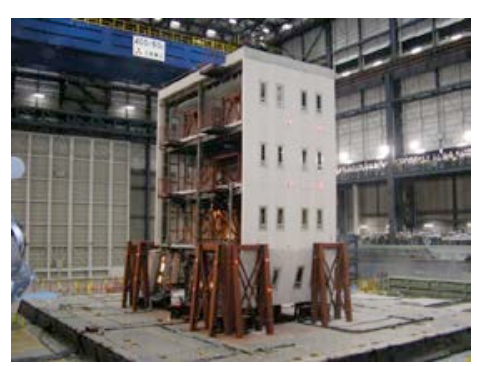

(a)

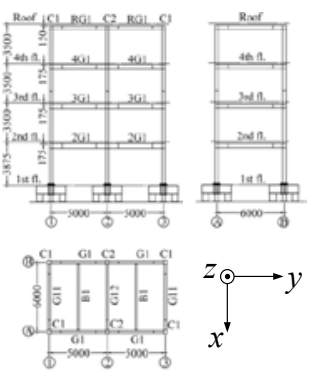

(b)

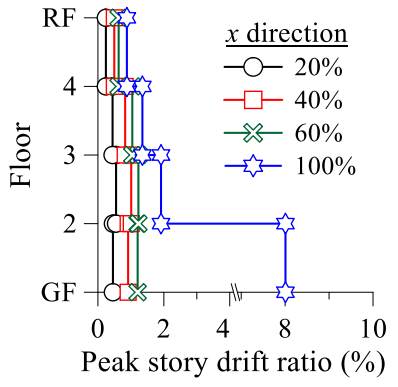

(c)

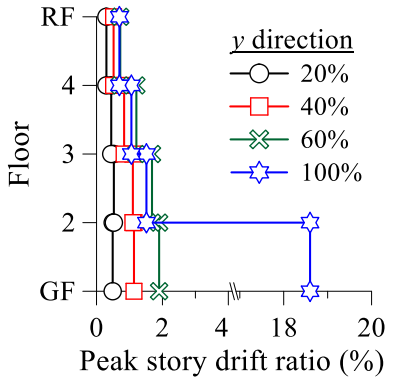

(d)

Fig. 1. Full-scale 4-story steel frame building: (a) overview of test setup; (b) plan and elevation view; (c) peak SDR distribution in the $x$ loading direction; and (d) peak SDR distribution in the $y$ loading direction.

Figures 1(c) and 1(d) illustrate the peak SDRs along the height of the test structure in the $x$ and $y$ loading directions, respectively. From these figures, the structural damage in the one-bay steel MRF [see Figure 1(c)] was less than that observed in the two-bay steel MRF [see Figure 1(d)]. The reason was that the east-west (E-W) component of the JR Takatori record, which was more damaging for the period range of interest, was applied in the $y$-loading direction. The test structure remained linear during the $20 \%$ scaled JR Takatori record and experienced minor flexural yielding at the base of its first story columns during the $40 \%$ scaled intensity. During the $60 \%$ scaled seismic intensity, the onset of local buckling was observed in the first story columns. Non-structural component damage was also evident. Finally, the test structure collapsed with a first-story sideway mechanism during the $100 \%$ of the unscaled JR Takatori record before it rested on the safety-catch "anti-collapse" frame as shown in Figure 1(a).

Table 1 summarizes the dynamic properties for the first two vibration modes of the 4 -story test structure. The ARX method is applied to the measured vibration data from a 3-D white noise excitation that was conducted prior to the main tests to estimate the dynamic characteristics of the building. Referring to Table 1, the computed dynamic properties are consistent with the values reported in prior studies (Suita et al. 2008; Lignos et al. 2013). 
This peer-reviewed published paper appears as: Hwang, S-H., Lignos, D.G. (2017). “Assessment of Structural Damage Detection Methods for Steel Structures Using Full-Scale Experimental Data and Nonlinear Analysis, Bulletin of Earthquake Engineering, https://doi.ong/10.1007/s10518-017-0288-2 (in-press).

Table 1 Natural frequencies and damping ratios of the test structures tested at full-scale at the E-Defense shake table.

\begin{tabular}{llllll}
\hline \multirow{2}{*}{ Reference } & \multirow{2}{*}{ Test specimen } & \multicolumn{2}{l}{ Natural frequency $(\mathrm{Hz})$} & \multicolumn{2}{c}{ Damping ratio $(\%)$} \\
\cline { 3 - 6 } & & First mode & Second mode & First mode & Second mode \\
\hline \multirow{2}{*}{ E-Defense (Suita et al. 2008$)$} & 4-story steel MRF ( $x$ loading direction) & 1.23 & 4.14 & 1.49 & 3.42 \\
& 4-story steel MRF $(y$ lading direction) & 1.30 & 4.23 & 2.85 & 3.14 \\
\hline E-Defense (Okazaki et al. 2013a) & Single-story CBF & 4.86 & -- & 5.29 & -- \\
\hline
\end{tabular}

3.2. Single-story, chevron concentrically braced frame

In order to investigate the applicability of damage identification techniques for assessing structural damage in steel frame buildings with CBFs, we utilize the test data from a single-story, single-span, chevron CBF conducted by Okazaki et al. (2013a). The test structure represents the lower story of a 3- to 5-story steel frame building with CBFs commonly used in Japan. The bracing connections of the steel CBF were designed in accordance with the balanced design procedure proposed in Lehman et al. (2008). Figures 2(a) and (b) show the CBF geometry and test bed, respectively. The test structure was subjected to a range of seismic intensities $(14 \%, 2 \times 28 \%, 42 \%$ and $70 \%)$ of the EW component of the JR Takatori record from the 1995 Kobe earthquake. Note that the test structure was subjected two times to the $28 \%$ of the unscaled JR Takatori intensity. Figure 2(c) shows the structural damage progression in terms of peak SDRs with respect to the ground motion intensity. During the lower seismic intensities of the JR Takatori record, the steel braces buckled globally as intended (i.e., brace buckling occurred during the $28 \%$ scaled record). During the $70 \%$ of the unscaled JR Takatori intensity, both steel braces fractured near their mid-length due to lowcycle fatigue. This caused a significant lateral strength and stiffness loss to the test structure. During this motion, the steel beam also yielded near the column face once the peak SDR exceeded 1\%. The reported damage progression reflects the typical one observed in code-compliant steel CBFs based on past reconnaissance reports and experimental studies related to the seismic performance of multi-story CBFs (Okazaki et al. 2013b; Lai and Mahin 2014; Sen et al. 2016). After earthquake-induced brace fracture the framing action was such that could maintain the overall lateral stability of the steel CBF. More details regarding the performance of the test structure as well as its design specifics can be found in Okazaki et al. (2013a).

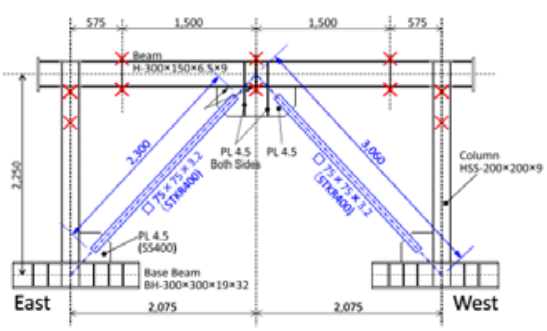

(a)

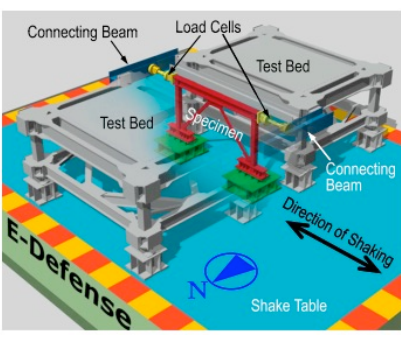

(b)

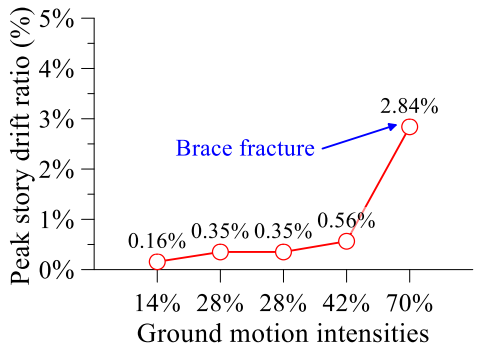

(c)

Fig. 2 Large-scale model of a single-story chevron CBF: (a) elevation view of test specimen (adopted from Okazaki et al. (2013a)); (b) test-bed system (adopted from Okazaki et al. (2013a)); and (c) peak SDRs at various ground motion intensities.

The natural frequency and the damping ratio of the undamaged test structure is tabulated in Table 1. Its dynamic characteristics are identified based on vibration response data obtained from a white noise excitation test. A singleinput/single-output ARX method was utilized for this purpose. Referring to Table 1, the test structure shows higher damping ratio (i.e., 5.3\% damping) compared to the PEER/ATC-72-1 (PEER/ATC 2010) modeling recommendations for structural damping (i.e., 2.0\% damping for structural steel systems with less than 30 stories). This is attributed to the measured friction between the slider and the test bed. This is further elaborated in Section 4.2. 
This peer-reviewed published paper appears as: Hwang, S-H., Lignos, D.G. (2017). “Assessment of Structural Damage Detection Methods for Steel Structures Using Full-Scale Experimental Data and Nonlinear Analysis, Bulletin of Earthquake Engineering, https://doi.ong/10.1007/s10518-017-0288-2 (in-press).

In an effort to highlight potential issues with damage identification techniques in multi-story steel buildings the experimental data discussed in the previous sections are complemented with numerical simulations of an 8 -story steel MRF building and a 3-story steel CBF building. These buildings have been deigned in accordance with the current North American seismic design practice (AISC 2010a, b) as standard office buildings in downtown Los Angeles.

Figure 3 illustrates a floor plan and elevation view of the two buildings. The 8-story steel building with perimeter MRF utilizes fully-restrained reduced beam section (RBS) moment connections designed according to ANSI/AISC 358-10 (AISC 2010a). The steel braces are designed with round hollow structural sections (HSS) arranged in a twostory X-bracing configuration. The gusset plate connections are designed with the balanced design procedure (Lehman et al. 2008). Details regarding the building designs can be found in Elkady and Lignos $(2014,2015)$ and NIST (2010).

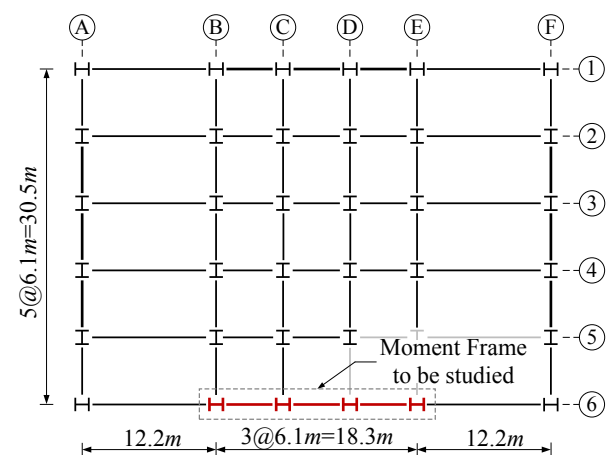

(a)

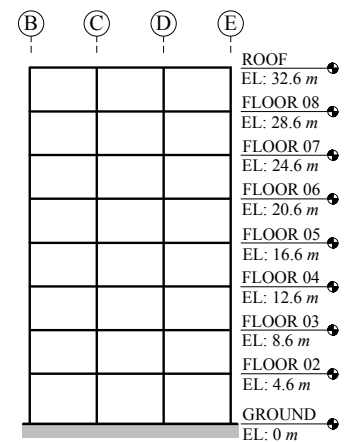

(c)

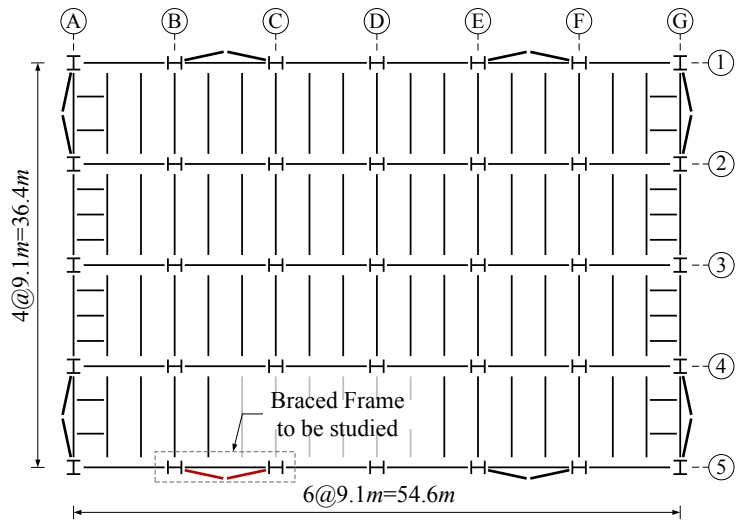

(b)

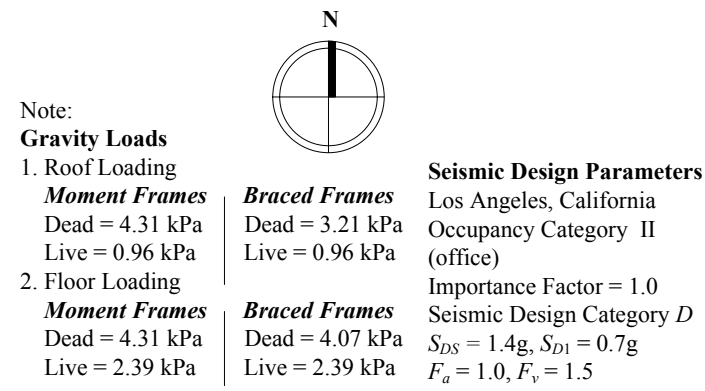

(d)

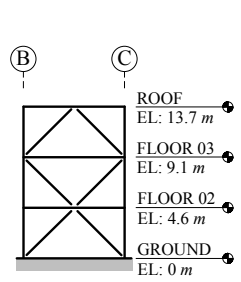

Fig. 3 Steel office buildings with perimeter MRF and CBF for supplementary case studies.

A 2-dimensional (2-D) numerical model of the steel frame buildings in the E-W direction [see Figures 4(a) and (b)] is developed in the Open System for Earthquake Engineering Simulation (OPENSEES) Platform (release version 2.5.0) (McKenna 1997). The steel beams and columns in the MRF are modeled as elastic elements with concentrated plasticity flexural hinges at their ends as shown in Figure 4(a). The modified Ibarra-Medina-Krawinkler phenomenological deterioration model (Ibarra et al. 2005; Lignos and Krawinkler 2011) is assigned to the nonlinear spring elements. The modeling approach has been thoroughly validated with steel MRF shake table collapse experiments in prior studies (Lignos et al. 2009, 2011, 2013).

The steel braces of the 3-story CBF are modeled as discussed in Karamanci and Lignos (2014). In brief, the nonlinear models explicitly simulate brace buckling and fracture initiation due to low-cycle fatigue, beam, and column cyclic deterioration in flexural strength as well as geometric nonlinearities. The nonlinear model specifics including the hysteretic response of a steel beam and a steel brace in comparison with experimental data is shown in Figure 4. The modeling approach in this case has been validated inelastic cyclic buckling and fracture component tests (Lignos 
This peer-reviewed published paper appears as: Hwang, S-H., Lignos, D.G. (2017). “Assessment of Structural Damage Detection Methods for Steel Structures Using Full-Scale Experimental Data and Nonlinear Analysis, Bulletin of Earthquake Engineering, https://doi.ong/10.1007/s10518-017-0288-2 (in-press). et al. 2012; Lignos and Karamanci 2013b) as well as large-scale shake table and quasi-static experiments on steel CBFs (Uriz 2005; Lignos et al. 2012; Okazaki et al. 2013a).

The dynamic response of the 8- and 3-story steel frame buildings is investigated based on multiple nonlinear response history analysis (NRHA) with earthquake records that represent the seismic hazard at the design location for both buildings. In particular, the numerical model of the 8-story steel MRF building is subjected to the 'IV79cal' ground motion record of the Calipatria Fire Station from the 1979 Imperial Valley earthquake in Southern California. The numerical model of the 3-story CBF building is subjected to the fault normal component of the Canoga Park record from the 1994 Northridge earthquake. It should be noted that although the ground motion records used in the virtual simulations are different than the ones employed in the shake table experiments discussed earlier, they pronounce the influence of higher mode effects on the dynamic response of the examined steel frame buildings. This is done in an attempt to highlight potential limitations of the damage indicators that are explored in Section 4. The EDPs of interest (i.e., peak SDRs, PFAs, residual SDRs) of each frame building are obtained for each ground motion from the onset of structural damage through the occurrence of structural collapse. Collapse herein is defined as the point that a story or a number of stories displace sufficiently such that P-Delta effects accelerated by component deterioration in strength and stiffness fully offset the first order story shear resistance of the steel MRF and CBF. This definition of collapse is consistent with prior shake table collapse experiments (Suita et al. 2008, Lignos et al. 2011, 2013).

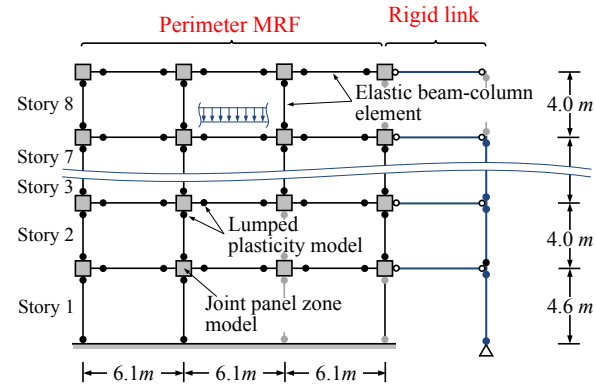

(a)

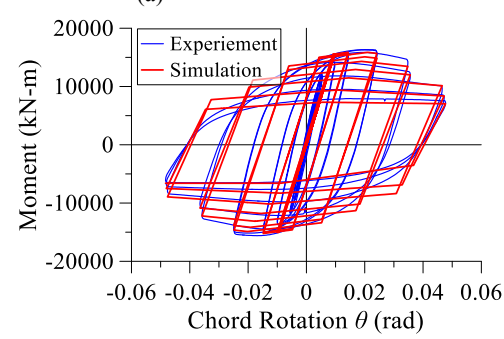

(c)

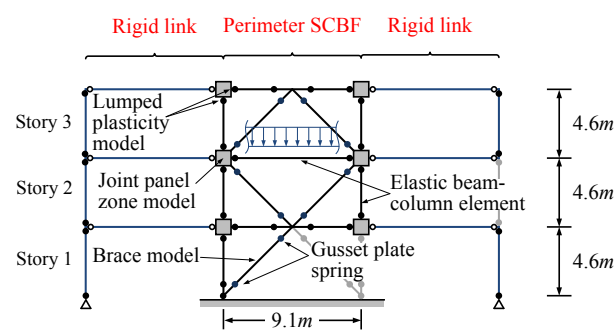

(b)

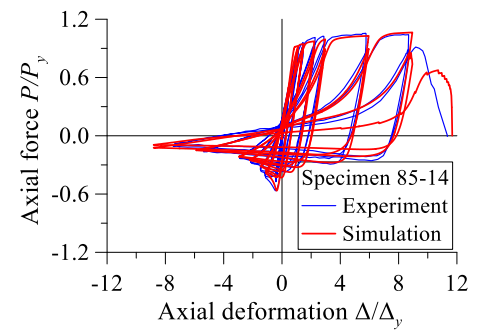

(d)

Fig. 4 Nonlinear building models of steel frame buildings: (a) 2-D model of 8-story steel frame building with MRFs; (b) 2-D model of 3-story steel frame building with CBFs; (c) validation of calibrated bare steel beam with RBS connection (data from Gilton et al. 2000); and (d) validation of calibrated steel HSS braces (data from Han et al. 2007).

Figure 5(a) illustrates the pseudo spectral acceleration, $S_{a}\left(T_{1}, 5 \%\right)$ at the first mode period of each frame building with respect to the absolute maximum SDR along the height of the frames at several ground motion intensities. The vertical axis is normalized with respect to the $S_{a}\left(T_{1}, 5 \%\right)$ corresponding to the design-basis seismic intensity. Referring to Figure 5, once the curves become flat, dynamic instability occurs (i.e., sidesway collapse). Figures 5(b) and 5(c) show the distribution of peak SDRs along the height of the steel MRF and CBF, respectively, at selected seismic intensities. From Figure 5(c), it is evident that the 3-story CBF tends to form a weak story due to the concentration of plastic deformations within the first story. Referring to Figure 5(b), the collapse mechanism of the 8-story steel MRF building involves its first three stories. The observed damage progression with respect to the increased seismic intensity is deemed to be representative of code-compliant steel frame buildings (NIST 2010). 
This peer-reviewed published paper appears as: Hwang, S-H., Lignos, D.G. (2017). “Assessment of Structural Damage Detection Methods for Steel Structures Using Full-Scale Experimental Data and Nonlinear Analysis, Bulletin of Earthquake Engineering, https://doi.ong/10.1007/s10518-017-0288-2 (in-press).

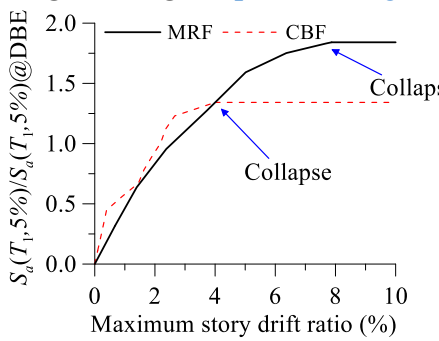

(a)

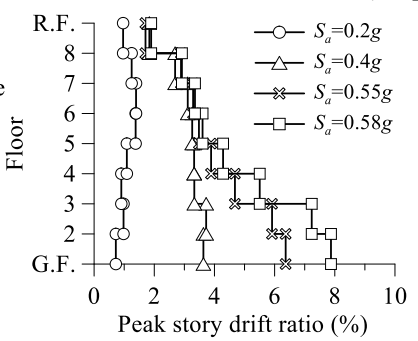

(b)

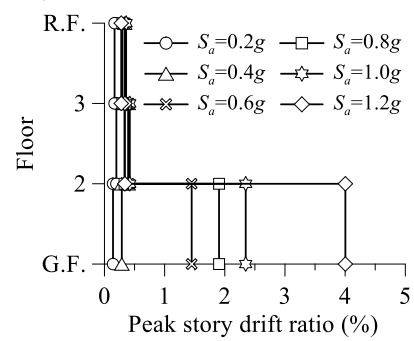

(c)

Fig. 5 Dynamic analysis and peak SDR distributions: (a) incremental dynamic analysis through collapse; (b) peak SDR distribution for the 8-story steel MRF at selected seismic intensities; and (c) peak SDR distribution for the 3-story CBF at selected seismic intensities.

\section{EFFICIENCY OF SYSTEM IDENTIFICATION TECHNIQUES FOR ASSESSING STRUCTURAL DAMAGE IN STEEL FRAME BUILDINGS}

This section examines the efficiency of the various system identification techniques presented in Section 2 for assessing the structural damage in code- compliant steel MRFs and CBFs at various ground motion intensities. The shifting in natural frequencies, damping ratios and mode shapes of the test structures are employed as potential damage indicators based on the FDD, ARX and N4SID system identification techniques. When the wavelet-based damage identification technique is employed, the normalized DSFs are utilized as potential damage indicators. In all the examined cases, the absolute floor acceleration response histories of the test structures are utilized for quantifying the corresponding damage indicator. Due to brevity, representative results obtained from few of the test structures discussed in Section 3 are presented in the subsequent sections. The discussion is grouped per lateral load-resisting system (i.e., steel $\mathrm{MRF} / \mathrm{CBF})$.

\subsection{Natural frequency as a damage indicator}

Figure 6 illustrates the identified dynamic properties of the 4-story steel MRF tested at E-Defense in the $y$-loading direction based on the three system identification algorithms discussed in Sections 2.1 to 2.3 (i.e., FDD, ARX and N4SID methods). The recorded absolute acceleration response data from a $0.08 g$ amplitude white noise excitation was utilized for this purpose. Referring to Figure 6, the identified dynamic properties of the undamaged state of the test structure are used as a reference for its structural damage detection. Figure 6(a) shows the singular values of the PSD function matrix of the white noise acceleration response data of the same frame. The identified natural frequency and damping ratio of the first vibration mode are nearly the same with those reported in Suita et al. (2008). Figures 6(b) and 6(c) illustrate the stabilization diagram as well as the dynamic properties of the undamaged state of the 4-story MRF. From a comparison of Figures 6(b) and 6(c), it is found that the estimated values based on the N4SID method are very close to those estimated based on the ARX method.

Figure 7 shows the identified natural frequencies based on the FDD, ARX and N4SID system identification techniques of the test structures with MRFs at various ground motion intensities. The corresponding decreases in the natural frequencies of these structures are quantified relative to the natural frequency of the undamaged state. Note that in the case of structural collapse, a truncated signal is employed for the system identification that contains the response history from the beginning of the motion to the point that the structural system loses its lateral stability (i.e., dynamic instability occurs). Referring to Figure 7, the results indicate that the natural frequencies for both the first and second modes of the steel MRFs decrease while the seismic intensity increases (i.e., structural damage of the test structures progressively develops) regardless of the employed system identification technique. This is to be expected due to the flexural yielding and the onset of local buckling at the corresponding beam-to-column connections as well as flexural yielding at the base of the first story columns. Notably, the observed steel MRF natural frequency changes are small regardless of the employed system identification technique even at seismic intensities associated with structural collapse. For the 4-story steel MRF that collapsed with a first-story collapse mechanism at the $100 \%$ of the 
This peer-reviewed published paper appears as: Hwang, S-H., Lignos, D.G. (2017). “Assessment of Structural Damage Detection Methods for Steel Structures Using Full-Scale Experimental Data and Nonlinear Analysis, Bulletin of Earthquake Engineering, https://doi.ong/10.1007/s10518-017-0288-2 (in-press). unscaled JR Takatori [see 100\% in Figure 7(a)] the corresponding decrease in the natural frequencies with respect to the ones of the undamaged state of the test structure is less than $40 \%$. Same observations hold true for the 8 -story steel MRF as shown in Figure 7(b).

Referring to Figure 7(a), till after the occurrence of flexural yielding (i.e., $60 \%$ of the JR Takatori seismic record), the frequency decrease is negligible. However, at this intensity the composite floor system cracked and the beam yielding was developed (Suita et al. 2008). This is not traced by any of the system identification techniques employed in this paper. The FDD method seems to only pick up a $12 \%$ decrease in the first mode natural frequency. Similarly, at the "collapse" seismic intensity (i.e., $100 \%$ of the JR Takatori seismic record) with a first-story collapse mechanism, only the FDD method picks up a 35\% decrease in the test structure's first natural frequency. As compared to the results obtained based on other system identification techniques (i.e., a 20\% decrease for the ARX and N4SID), a larger decrease may be due to modeling and estimation errors in the FDD method in which the input excitation is assumed to be ideally white noise and stationary. It should be stated that according to the fundamentals of the dynamic analysis of stability, the eigen frequency of the equivalent elastic structure should be either zero or imaginary while the structure becomes unstable (Bažant and Cedolin 1991).
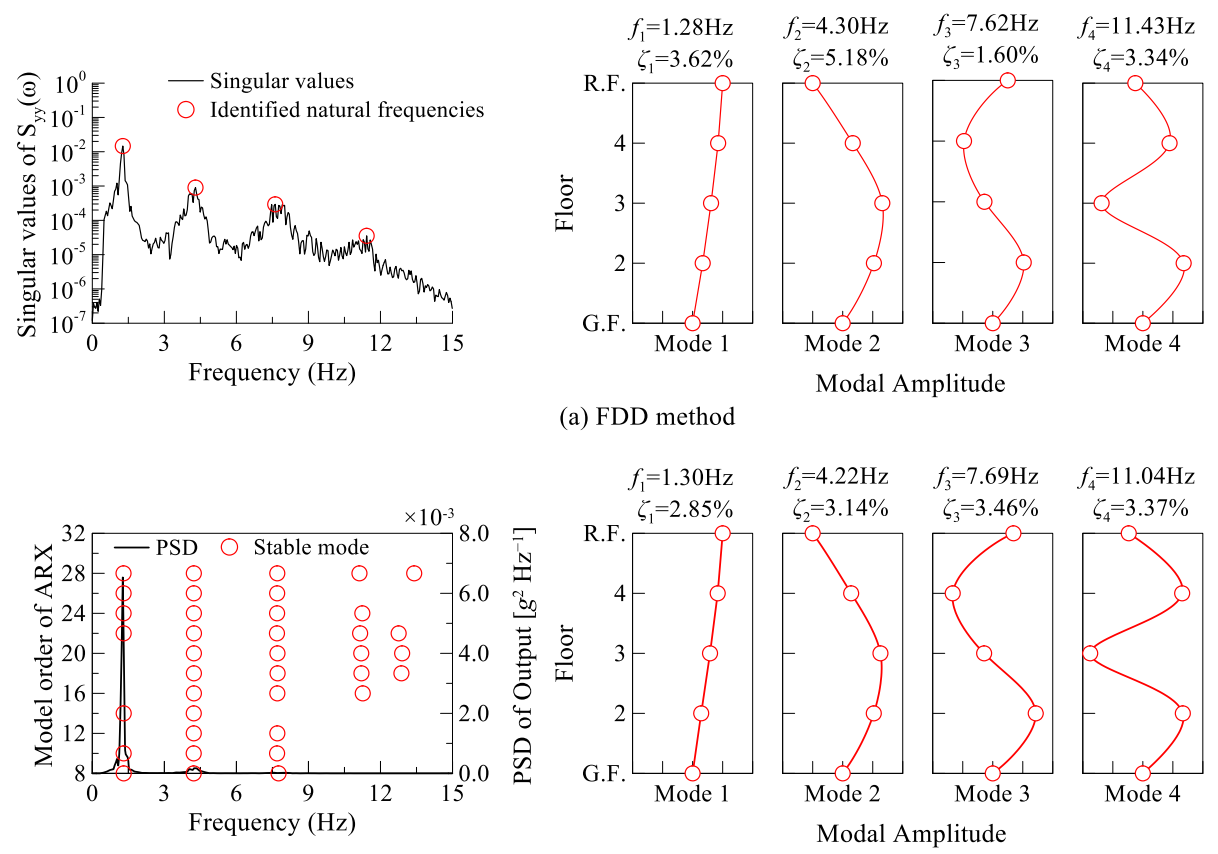

(b) ARX method
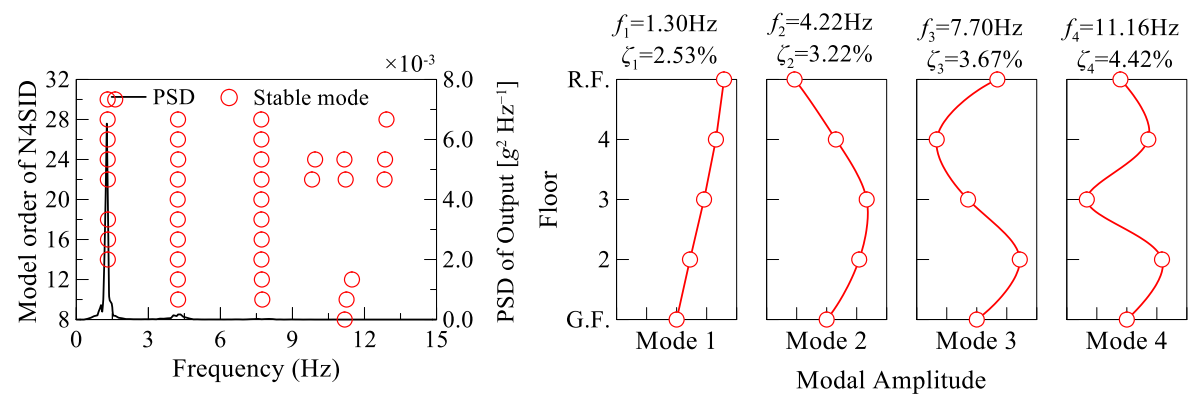

(c) N4SID method

Fig. 6 Natural frequencies, mode shapes and damping ratios of the 4-story steel MRF building ( $y$ loading direction) tested at E-Defense. 
This peer-reviewed published paper appears as: Hwang, S-H., Lignos, D.G. (2017). “Assessment of Structural Damage Detection Methods for Steel Structures Using Full-Scale Experimental Data and Nonlinear Analysis, Bulletin of Earthquake Engineering, https://doi.ong/10.1007/s10518-017-0288-2 (in-press).

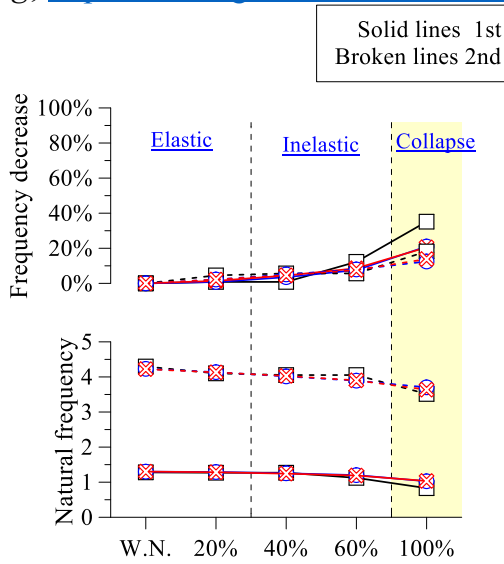

(a) 4-story MRF

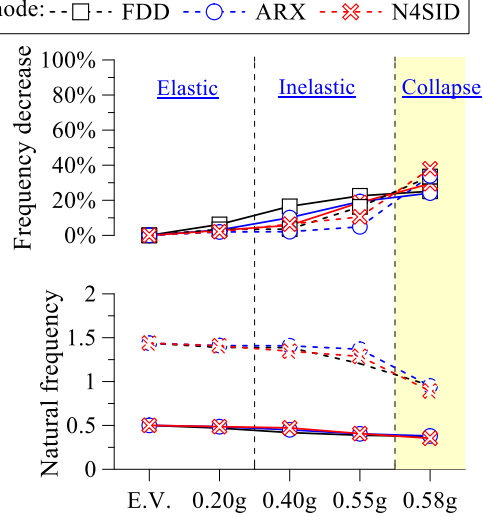

(b) 8-story MRF

Fig. 7 Identified natural frequency and its decrease in steel MRF buildings.

From a comparison of Figures 7(a) and 7(b), the change in the natural frequency of the 4-story steel MRF tested at E-Defense is more rapid than that of the 8-story steel MRF. This is due to the fact that the former collapsed with a first-story mechanism; while the latter collapsed with a three-story collapse mechanism. However, Figure 7 suggests that prior to structural collapse the lateral stiffness of code- compliant steel MRFs is not very sensitive to the damage progression of beam-to-column connections conditioned that the latter is attributed to flexural yielding and local buckling (i.e., ductile failure modes). This is also confirmed from Table 2 that tabulates the first two natural frequencies of the 8-story steel MRF based on the various system identification methods as well as eigenvalue analysis that was conducted once the steel MRF rested after the end of each ground motion. Notably, Rodgers and Çelebi (2006) reached to similar conclusions based on work done on instrumented steel MRF buildings with low instrumentation density that experienced actual earthquake events. They also indicated that a decrease in the building's natural frequency extracted from vibration-based methods did not provide sufficient information regarding the identification of localized damage on the structural components (i.e., weld defects and small cracks in moment connections) of the instrumented building. Same observations hold true for the 8-story steel MRF as shown in Figure 7(b). Due to the steel beam lateral bracing requirements (AISC 2010b), lateral-torsional buckling was not triggered. This failure mode strongly influences the unloading stiffness of a steel beam and therefore the overall lateral stiffness of a steel MRF (Lignos and Krawinkler 2011).

Table 2 Comparisons of estimated natural frequencies for the 8-story MRF test structure

\begin{tabular}{lccccc}
\hline \multirow{2}{*}{ Method } & \multirow{2}{*}{ Mode } & \multicolumn{4}{c}{ Seismic Intensity } \\
\cline { 3 - 5 } & & $S_{a}=0.20 g$ & $S_{a}=0.40 g$ & $S_{a}=0.55 g$ & $S_{a}=0.58 g$ \\
\hline FDD & 0.470 & 0.418 & 0.388 & 0.375 \\
ARX & 0.486 & 0.472 & 0.407 & 0.353 \\
N4SID & \multirow{2}{*}{$1^{\text {st }}$ mode } & 0.485 & 0.450 & 0.404 & 0.380 \\
OPENSEES & & 0.488 & 0.487 & 0.454 & -- \\
\hline FDD & & 1.389 & 1.387 & 1.205 & 0.955 \\
ARX & & 1.408 & 1.346 & 1.286 & 0.892 \\
N4SID & \multirow{2}{*}{$2^{\text {nd }}$ mode } & 1.410 & 1.408 & 1.368 & 0.950 \\
OPENSEES & & 1.411 & 1.408 & 1.374 & -- \\
\hline
\end{tabular}

Figures 8(a) and 8(b) show the identified natural frequencies and the corresponding frequency decrease of the test structures with CBFs discussed in Sections 3.2 and 3.3. The steel brace damage state (i.e., elastic, brace buckling, brace fracture) is also indicated in the same figure to facilitate the subsequent discussion. Referring to Figure 8(a), the natural frequency decrease is practically negligible at low seismic intensities associated with a service-level earthquake (SLE) (i.e., 28\% of the JR Takatori record). This is to be expected considering that the seismic response of the steel CBF was essentially elastic in this range. However, large decreases in the steel CBF natural frequencies are observed at seismic 
This peer-reviewed published paper appears as: Hwang, S-H., Lignos, D.G. (2017). “Assessment of Structural Damage Detection Methods for Steel Structures Using Full-Scale Experimental Data and Nonlinear Analysis, Bulletin of Earthquake Engineering, https://doi.ong/10.1007/s10518-017-0288-2 (in-press). intensities that steel brace flexural buckling occurred. This geometric instability is associated with an appreciable loss of lateral stiffness of the CBF (Tremblay 2002; Lignos and Karamanci 2013a); the corresponding frequency decrease in this case is on the order of $20 \%$ at a seismic intensity of the $42 \%$ JR Takatori record [see Figure 8(a)]. Referring to Figure 8(b), the frequency decrease of the 3-story $\mathrm{CBF}$ at the seismic intensities associated with a design-basis earthquake (DBE) (i.e., $S_{a}\left(T_{1}, 5 \%\right)=0.9 g$ ) is on the order of $30 \%$ regardless of the employed system identification technique.

Referring to Figure 8, when at ultimate limit states (i.e., steel brace fracture) the corresponding fundamental frequency decrease is at least $60 \%$ with respect to that of the undamaged state. Steel brace fracture is associated with a considerable loss of the steel CBF's lateral stiffness (Karamanci and Lignos 2014), and thus causes a significant decrease in the fundamental frequency of the steel CBF building. This indicates that damage identification techniques that rely on natural frequency changes can be promising in cases that the damage progression is associated with a rapid loss of lateral stiffness such as that observed in steel CBFs. This is not the case in code- compliant steel MRFs. In any case, the challenge of mapping story-based EDPs with frequency decreases for structural and non-structural damage control still remains.

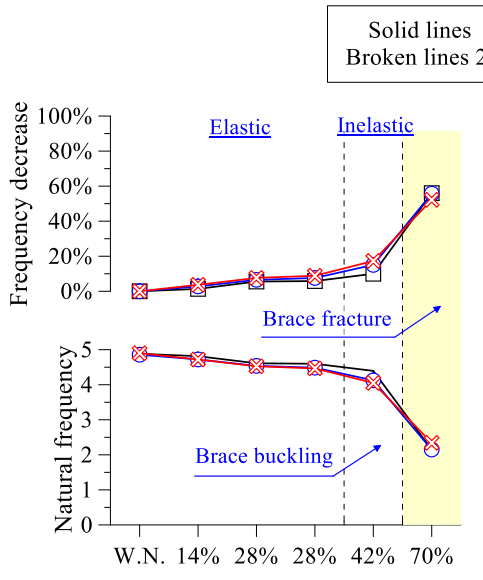

(a) Single-story CBF

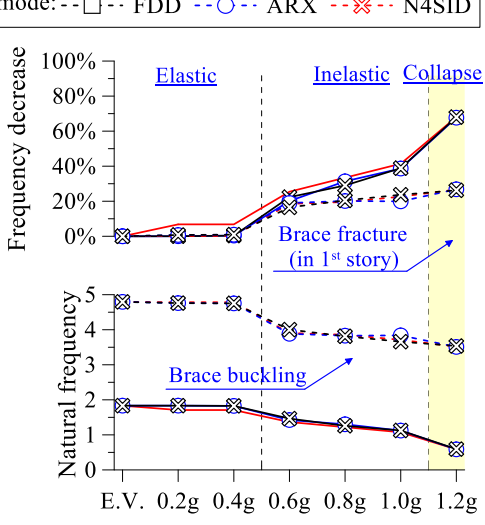

(b) 3-story CBF

Fig. 8 Identified natural frequency and frequency decrease in steel CBFs.

\subsection{Equivalent damping ratio \& mode shapes as damage indicators}

This section evaluates the efficiency of the damping ratio as a potential damage indicator for steel MRFs and CBFs. Conceptually, the equivalent viscous damping ratio increases when a structure behaves in its inelastic regime. This is due to the hysteretic energy dissipated through flexural yielding and buckling of beam-to-column connections and steel braces, respectively.

Figure 9 shows the equivalent viscous damping ratios at various ground motion intensities based on the employed system identification techniques for the steel MRFs examined in this paper. The first mode equivalent viscous damping ratio in steel MRFs increases while the seismic intensity increases. Referring to Figures 9(a) and 9(b), depending on the employed system identification technique, the damping increase for the 4-story steel MRF is $17 \%$ to $106 \%$ for a design-basis earthquake in Japan (i.e., $40 \%$ of the JR Takatori record); the corresponding increase for the 8-story MRF is $85 \%$ to $175 \%$ at a DBE seismic intensity (i.e., $S_{a}\left(T_{1}, 5 \%\right)=0.40 \mathrm{~g}$ ). The former includes the composite floor slab as well as non-structural components (i.e., ALC panels of the exterior walls and drywall partitions); the latter considers the bare steel MRF only. Minor flexural yielding was observed only at the first story column bases of the 4-story steel MRF. The second floor panel zones also yielded in shear at the same intensity. Therefore, at frequent seismic events damage in the composite slab and the non-structural content may mostly contribute to the energy dissipation. From Figure 9(a), these effects diminish at low probability of occurrence seismic intensities. The reason is that hysteretic energy dissipation due to flexural yielding and local buckling of the steel columns and beam-to-column joint panel 
This peer-reviewed published paper appears as: Hwang, S-H., Lignos, D.G. (2017). “Assessment of Structural Damage Detection Methods for Steel Structures Using Full-Scale Experimental Data and Nonlinear Analysis, Bulletin of Earthquake Engineering, https://doi.ong/10.1007/s10518-017-0288-2 (in-press). zones becomes significant. In the case of the 8-story MRF building, at a DBE intensity a number of structural elements participate into the hysteretic energy dissipation because the distribution of peak SDRs is more or less uniform along the height of the MRF [see Figure 5(b)].

Referring to Figure 9(a), at seismic intensities associated with structural collapse, the computed equivalent damping ratios are highly dependent on the employed system identification technique. Notably, the 8-story steel MRF develops a collapse mechanism that involves three stories and therefore more structural elements participate into the energy dissipation. However, the 4-story steel MRF tested at E-Defense collapsed with a first story mechanism; therefore, only limited number of elements (i.e., primarily the first story columns) dissipated hysteretic energy prior to collapse. These fundamental differences in the energy dissipation mechanisms of the two steel MRFs prior to the occurrence of structural collapse are not reflected well in the equivalent viscous damping ratios.

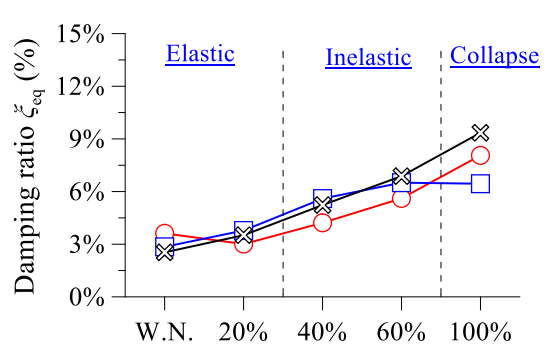

(a) 4-story MRF

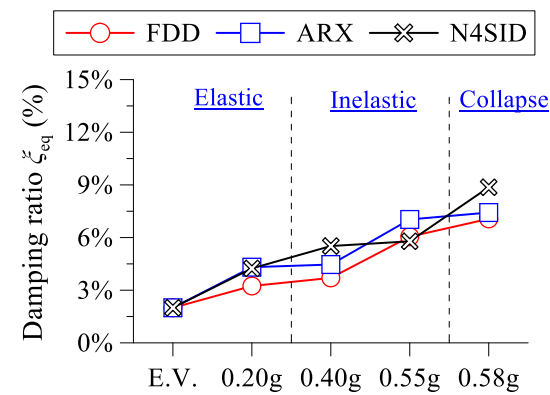

(b) 8-story MRF

Fig. 9 Estimated damping ratio of the first mode for test structures with MRFs: (a) $y$-loading direction of the 4-story MRF building at E-Defense facility; and (b) numerical model of the 8 -story MRF building.

Figure 10 shows the equivalent damping ratios for the single- and 3-story CBFs. The first mode equivalent damping ratios in steel CBFs tend to increase with respect to the increased ground motion intensity. However, in cases that friction damping contributes to the energy dissipation the equivalent viscous damping ratio could be misleading. In particular, if the ground motion intensity is small the equivalent viscous damping ratio would still be large indicating that there could be structural damage even though this would not be the case. This is shown in Figure 10(a) for the single-story steel CBF tested at E-Defense. The white noise test indicates that the equivalent viscous damping ratio is fairy high (i.e., it ranges between $5.3 \%$ and $6.6 \%$ ) regardless of the employed system identification technique. This is due to the friction of the test bed to the sliders (Okazaki et al. 2011, 2013a). However, this issue diminishes after the $14 \%$ of the unscaled JR Takatori record because the inertia forces become larger than the corresponding friction forces. This issue is evident from the dynamic response of the 3-story CBF numerical model at very small seismic intensities (i.e., $0.2 g$ ). Because its numerical model represents the bare frame only (i.e., no friction exists), viscous damping only contributes to the system energy dissipation. This is successfully traced by the employed system identification techniques.

Referring to Figure 10, the equivalent damping ratios remain practically the same if steel brace buckling does not occur. From the same figure, once brace flexural buckling occurs then there is a clear increase in the equivalent damping ratios. Contrary to the natural frequencies of the steel CBFs, the equivalent damping ratio seems to be insensitive to ultimate damage states associated with brace fracture. This observation holds true regardless of the employed system identification technique. 
This peer-reviewed published paper appears as: Hwang, S-H., Lignos, D.G. (2017). “Assessment of Structural Damage Detection Methods for Steel Structures Using Full-Scale Experimental Data and Nonlinear Analysis, Bulletin of Earthquake Engineering, https://doi.ong/10.1007/s10518-017-0288-2 (in-press).

$-\mathrm{O}-\mathrm{FDD}-\square-\mathrm{ARX} \leadsto-\mathrm{N} 4 \mathrm{SID}$

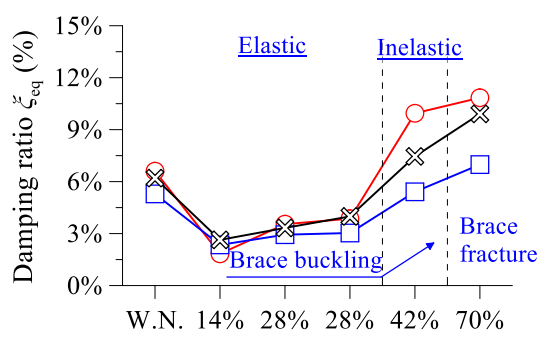

(a) Single-story CBF

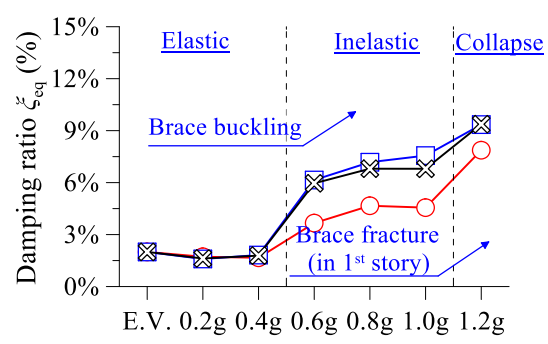

(b) 3-story CBF

Fig. 10 Estimated damping ratio of the first mode for CBFs: (a) single-story CBF at E-Defense facility; and (b) numerical model of the 3-story CBF.

Another dynamic property of a structure that has been historically used as a potential damage indicator is the modal assurance criterion (MAC) that quantifies the degree of linearity between two modal vectors (Allemang and Brown 1982). The one associated with a damaged structure and that associated with the mode shape of the undamaged one. The MAC values vary between 0 (indicating no consistent correspondence) and 1 (indicating a consistent correspondence). In the context of this paper, the MAC values are calculated for the mode shapes of each test structure at various ground motion intensities with respect to those of the corresponding undamaged state. Note that a MAC value larger than 0.9 indicates high consistent correspondence (Allemang and Brown 1982).

Table 3 tabulates the MAC values estimated for the examined steel MRFs. From this table, the observed changes in the steel MRF mode shapes is not significant even prior to structural collapse (i.e., all MAC values are larger than 0.9 regardless of the employed ground motion intensity). This is because the mode shape changes are small if the structural damage is distributed over the height of a frame structure. This is consistent with findings from prior studies (Ji et al. 2011). As stated earlier, another reason is the fact that in code- compliant steel MRFs designed in highly seismic regions, due to beam lateral bracing requirements, lateral torsional buckling does not typically occur. This geometric instability is associated with considerable changes in a steel MRF's lateral flexural stiffness (Lignos and Krawinkler 2011).

Table 3 Comparisons of estimated mode shapes based on the modal assurance criterion for the steel MRFs.

\begin{tabular}{llllllll}
\hline \multirow{2}{*}{ Test structure } & Loading & \multicolumn{2}{l}{ FDD method } & ARX method & \multicolumn{2}{l}{ N4SID method } \\
\cline { 2 - 7 } & intensity & 1st mode & 2nd mode & 1st mode & 2nd mode & 1st mode & 2nd mode \\
\hline \multirow{3}{*}{ 4-story loading } & $20 \%$ & 1.000 & 0.999 & 0.999 & 1.000 & 1.000 & 1.000 \\
y direction & $40 \%$ & 0.999 & 1.000 & 1.000 & 1.000 & 1.000 & 1.000 \\
& $60 \%$ & 1.000 & 1.000 & 1.000 & 1.000 & 1.000 & 1.000 \\
& $100 \%$ & 0.985 & 0.984 & 0.986 & 0.996 & 0.923 & 0.994 \\
\hline \multirow{5}{*}{ 8-story steel MRF } & $0.20 g$ & 0.999 & 0.998 & 1.000 & 1.000 & 1.000 & 0.999 \\
& $0.40 g$ & 0.993 & 0.968 & 1.000 & 0.931 & 1.000 & 0.999 \\
& $0.55 g$ & 0.975 & 0.949 & 0.998 & 0.999 & 1.000 & 0.999 \\
\hline
\end{tabular}

Table 4 summarizes the MAC values for the first two modes of vibration of the 3-story CBF at a given ground motion intensity. From this table, the MAC values consistently decrease with the progression of structural damage due to brace flexural buckling. However, the MAC values are still larger than 0.9 indicating a consistent correspondence. From Table 4, at ultimate damage states associated with brace fracture, the MAC values of the second mode of vibration become less than 0.9 regardless of the employed system identification method. This is primarily attributed to the sudden loss of lateral stiffness of the corresponding CBFs due to steel brace fracture. Therefore, the MAC value shall only be used as an indicator for structural damage assessment of steel CBFs subjected to seismic intensities with a low probability of occurrence as well as moderately ductile steel CBFs (Bradley et al. 2014). The former exhibit severe structural damage due to brace fracture; the latter typically experience non-ductile failure modes. In both cases, the extent of structural damage may potentially result into significant changes of the steel CBF lateral stiffness. 
This peer-reviewed published paper appears as: Hwang, S-H., Lignos, D.G. (2017). “Assessment of Structural Damage Detection Methods for Steel Structures Using Full-Scale Experimental Data and Nonlinear Analysis, Bulletin of Earthquake Engineering, https://doi.ong/10.1007/s10518-017-0288-2 (in-press). of the instrumentation (Rodgers and Çelebi 2006).

Table 4 Comparisons of estimated mode shapes based on modal assurance criterion for the 3-story CBF test structure

\begin{tabular}{|c|c|c|c|c|c|c|c|}
\hline \multirow{2}{*}{ Test structure } & \multirow{2}{*}{$\begin{array}{l}\text { Loading } \\
\text { intensity }\end{array}$} & \multicolumn{2}{|c|}{ FDD method } & \multicolumn{2}{|c|}{ ARX method } & \multicolumn{2}{|c|}{ N4SID method } \\
\hline & & 1st mode & 2nd mode & $1 \mathrm{st}$ mode & 2nd mode & 1st mode & 2nd mode \\
\hline \multirow{6}{*}{ 3-story CBF simulation } & $0.2 g$ & 0.997 & 0.999 & 1.000 & 0.999 & 1.000 & 0.999 \\
\hline & $0.4 g$ & 0.997 & 0.999 & 1.000 & 0.999 & 1.000 & 0.999 \\
\hline & $0.6 g$ & 0.979 & 0.953 & 0.981 & 0.954 & 0.985 & 0.963 \\
\hline & $0.8 g$ & 0.966 & 0.948 & 0.973 & 0.944 & 0.966 & 0.942 \\
\hline & $1.0 g$ & 0.957 & 0.931 & 0.960 & 0.926 & 0.953 & 0.921 \\
\hline & $1.2 g$ & 0.927 & 0.897 & 0.927 & 0.898 & 0.926 & 0.899 \\
\hline
\end{tabular}

\subsection{Wavelet-based DSFs as a damage indicator}

The structural damage identification of the examined structures is evaluated through wavelet-based DSFs with different normalization methods (i.e., noted as $\mathrm{DSF}_{1}$ and $\mathrm{DSF}_{2}$ ). For this purpose, the first natural frequency, $f_{1}$ of the undamaged state of a structure is needed. This frequency corresponds to the scale $\hat{a}$ at which the wavelet energy is computed over time (see Section 2.4). For this purpose, the first natural frequency, $f_{1}$ of the test structures is obtained based on the ARX method. Due to brevity, results for selected test structures are presented in this section.

Figure 11 illustrates the wavelet-based $\mathrm{DSF}_{1}$ with respect to the corresponding ground motion intensity for the test structures examined in this paper. In the same figure, the corresponding peak SDRs of the respective structure per seismic intensity are shown in a dual plot. Referring to Figure 11(a), $\mathrm{DSF}_{1}$ depicts the observed steel MRF structural damage due to flexural yielding of steel beams and columns and due to composite slab cracking at the $60 \%$ of the unscaled JR Takatori record. A DSF $1=0.3$ to 0.4 can be employed for a peak SDR range of $0.5 \%$ to $1.7 \%$. This is consistent with the 8-story steel MRF [see Figure 11(b)] as well as other steel MRF studies (Noh et al. 2012). Referring to Figure 11(a), even though the 4-story steel MRF collapsed with a first-story mechanism at a $100 \%$ of the JR Takatori record, the wavelet-based $\mathrm{DSF}_{1}$ values at all floors changed remarkably. Referring to Figure 11(d), same observation holds true for the 3-story CBF that collapsed with a first story collapse mechanism due to inelastic buckling and fracture of its first-story steel braces. From Figures 11(a) and 11(d), the small differences in $\mathrm{DSF}_{1}$ values obtained at other floors suggest that $\mathrm{DSF}_{1}$ can only be used with confidence as a global damage indicator.

Referring to Figure 11(b), the wavelet-based $\mathrm{DSF}_{1}$ at all floors of the 8-story steel MRF increases from 0 to 1 while the intensity of the input ground motion increases. This implies that the wavelet energy at scale $\hat{a}$ (i.e., the scale corresponding to the first natural frequency) decreases while the structural damage progresses. A $\mathrm{DSF}_{1}$ value on the order of 0.4 to 0.5 corresponds to a peak SDR of about $2 \%$ to $2.5 \%$. This drift range is typical in steel MRFs subjected to DBE seismic intensities (ASCE 2010; NIST 2010). Similarly, a $\mathrm{DSF}_{1}$ value of 0.7 to 0.8 corresponds to at least $5 \%$ peak SDR. This drift range could be expected in steel MRFs subjected to low probability of occurrence ground motions (i.e., MCE seismic intensities). Same observations hold true for the 4-story steel MRF as shown in Figure 11(a).

Referring to Figures 11(c) and 11(d), when steel CBFs ranging from 1 to 3 stories are subjected to DBE seismic intensities, a DSF 1 value of 0.1 to 0.2 imply that steel brace flexural buckling is likely to occur with limited out-ofplane brace rotation (i.e., 3\% out-of-plane brace rotation). This is important to note considering that at such rotations it is not easy to identify structural damage due to flexural buckling of steel braces because they may be hidden behind non-structural partition walls. For seismic intensities associated with low probability of occurrence earthquakes, a $\mathrm{DSF}_{1} \geq 0.6$ seems appropriate. At such intensities, steel brace fracture is likely to occur and therefore this is reflected in the computed $\mathrm{DSF}_{1}$ values. 
This peer-reviewed published paper appears as: Hwang, S-H., Lignos, D.G. (2017). “Assessment of Structural Damage Detection Methods for Steel Structures Using Full-Scale Experimental Data and Nonlinear Analysis, Bulletin of Earthquake Engineering, https://doi.ong/10.1007/s10518-017-0288-2 (in-press).

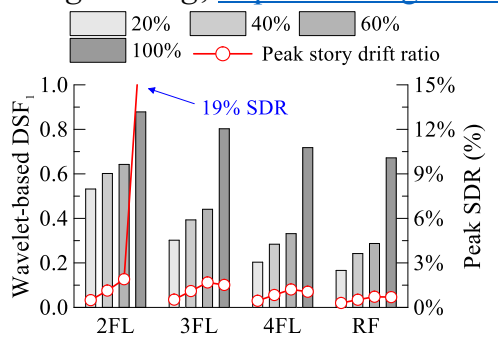

(a) 4-story MRF

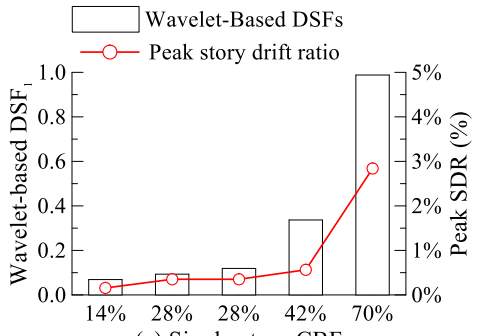

(c) Single-story CBF

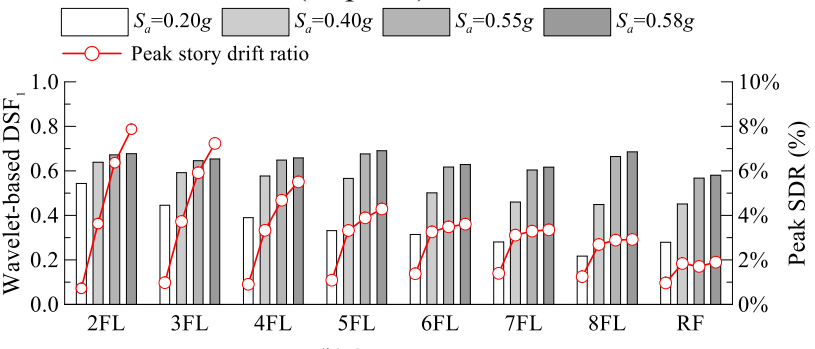

(b) 8-story MRF

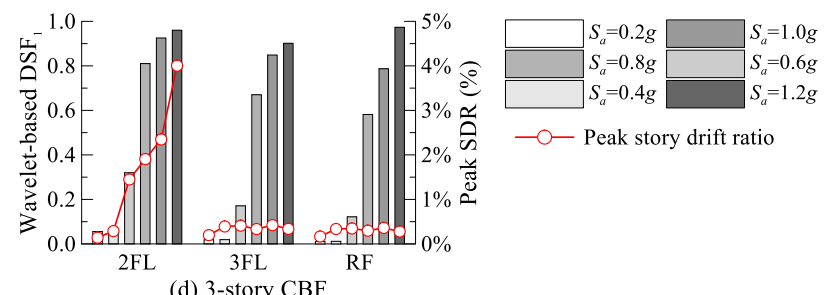

(d) 3-story CBF

Fig. 11 Wavelet-based $\mathrm{DSF}_{1}$ for all the test structures.

Figure 12(a) illustrates a comparison between the wavelet-based $\mathrm{DSF}_{1}$ and $\mathrm{DSF}_{2}$ for the single-story CBF. From this figure, the choice of the employed DSF seems to be important for seismic intensities associated with frequently occurring seismic events (i.e., $14 \%$ to $28 \%$ of JR Takatori record). In such cases, $\mathrm{DSF}_{2}$ is insensitive to moderate structural damage. The reason is that the sum of the wavelet energy at all dyadic scales $\left[E_{\text {tot }}=\sum_{j=M}^{N} E_{\text {scale }\left(a^{j}\right)}\right.$ in Eq. (14)] may not appropriately represent the total wavelet energy of the recorded response data. This can be further explained based on the PSD of the absolute floor acceleration response history of the single-story CBF at $14 \%$ of the JR Takatori record as shown in Figure 12(b). From this figure, we can examine the power distribution of the acceleration response data over a frequency range. The pseudo-frequencies corresponding to the natural frequency of the undamaged single-story CBF and the dyadic scales are superimposed in Figure 12(b). From this figure, the power of the absolute acceleration response at the roof of the single-story CBF is concentrated near its first natural frequency. Very low or nearly zero power of the acceleration response data concentrates at pseudo-frequencies that correspond to the dyadic scales. Therefore, Eq. (12) may lead to negative wavelet-based DSF values, if dyadic scales are utilized to calculate the total wavelet energy $E_{\text {tot. }}$. In this case, the DSF values should be forced to be zero. When this assumption is applied to $\mathrm{DSF}_{2}$ (i.e., noted as modified $\mathrm{DSF}_{2}$ ) then at low seismic intensities this DSF indicates no damage. The modified $\mathrm{DSF}_{2}$ is superimposed in Figure 12(a). Differences between $\mathrm{DSF}_{1}$ and $\mathrm{DSF}_{2}$ become minor at low probability of occurrence seismic intensities. In this case, the choice of the wavelet-based DSF is not critical. Same observations hold true for the rest of the test structures that were examined in this paper.

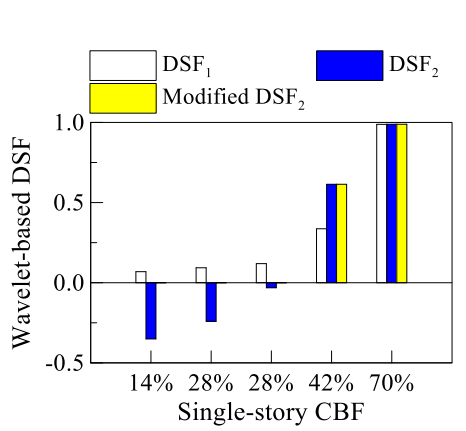

(a)

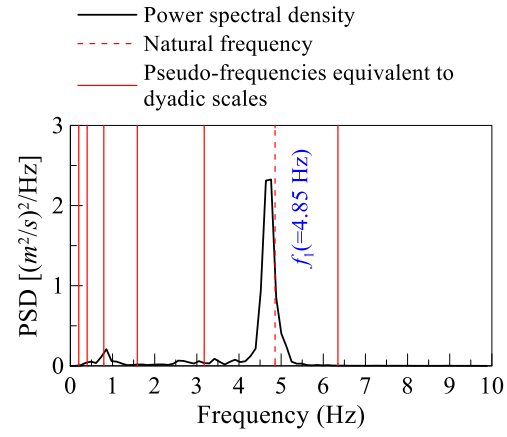

(b)

Fig. 12 Wavelet-based DSFs and PSD of the single-story CBF at E-Defense facility. 
This peer-reviewed published paper appears as: Hwang, S-H., Lignos, D.G. (2017). “Assessment of Structural Damage Detection Methods for Steel Structures Using Full-Scale Experimental Data and Nonlinear Analysis, Bulletin of Earthquake Engineering, https://doi.ong/10.1007/s10518-017-0288-2 (in-press).

Figure 13 shows the PSDs of the 8-story steel MRF for two different ground motions. It is noted from this figure that the power distribution of the acceleration response over a frequency range is significantly varied depending on the frequency content of the ground motion. At the lowest seismic intensity [i.e., $S_{a}\left(T_{1}, 5 \%\right)=0.1 g$ ], the building is mostly governed by the third and second modes for the 'IV79cal' and the 'IV79chi' ground motions, respectively; therefore, the wavelet-based $D S F_{1}$ discussed by Noh et al. (2011) requires further refinement to be employed in buildings with significant contribution from higher mode effects into their seismic response. To investigate this issue, the 8 -story steel MRF is further utilized.

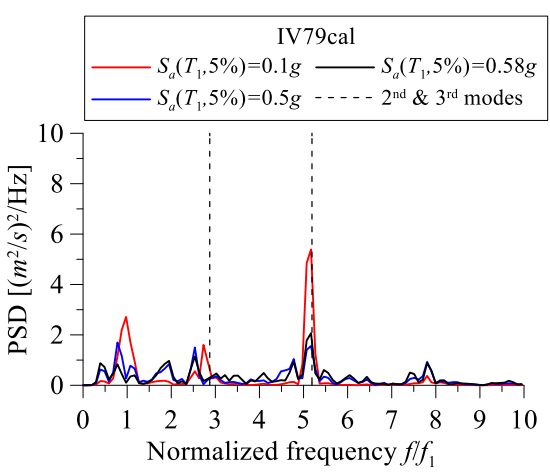

(a)

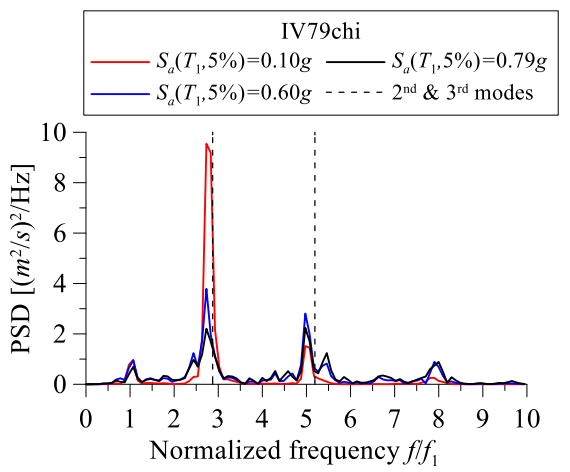

(b)

Fig. 13 Power spectral densities of the 8-story steel MRF subjected to two different ground motions: (a) IV79cal; and (b) IV79chi.

In order to determine the frequency shifting due to the higher mode effect contribution, the logarithmic difference of the PSD over the frequency range is determined based on the responses from a set of 40 ground motions relative to that extracted from a $0.1 \mathrm{~g}$ amplitude white noise excitation for the 8 -story steel MRF. The 40 ground motions represent the seismic hazard of the design location of the 8-story steel MRF and were assembled in a prior study (Medina and Krawinkler 2003). The logarithmic difference at frequency $j\left(\varepsilon_{\mathrm{ln}_{j}, j}\right)$ is determined as follows,

$$
\varepsilon_{\mathrm{ln}, j}=\sqrt{\frac{1}{n} \sum_{i=1}^{n}\left(\ln \left(\frac{P S D_{\text {white }, j}}{P S D_{N R H A, j}}\right)\right)^{2}}
$$

in which $n$ is the number of nonlinear response history analyses conducted for the set of 40 ground motions; $\mathrm{PSD}_{\text {white }} j$ is the power spectral density at the frequency $j$ extracted from a white noise excitation test; $\operatorname{PSD}_{N R H A, i, j}$ is the power spectral density at the frequency $j$ extracted from the $i$ th NRHA.

Figure 14 shows the logarithmic difference of the 8-story steel MRF. In this figure, the frequency, $f$, is normalized with respect to the first natural frequency, $f_{l}$, of the 8-story steel MRF. Based on the fluctuation of the logarithmic difference in the power distribution of the acceleration response of the 8-story steel MRF, the power at the second and third modes shifts to $2 f_{1}$ and $4.5 f_{1}$, respectively.

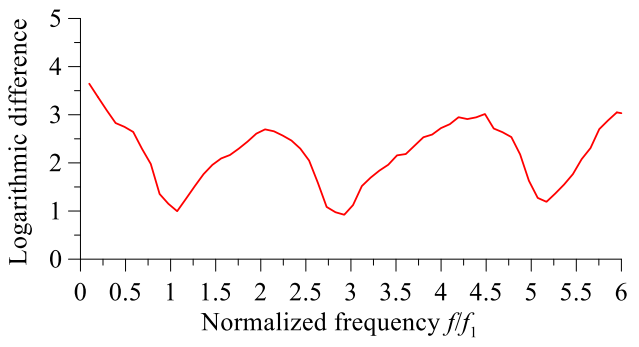


This peer-reviewed published paper appears as: Hwang, S-H., Lignos, D.G. (2017). “Assessment of Structural Damage Detection Methods for Steel Structures Using Full-Scale Experimental Data and Nonlinear Analysis, Bulletin of Earthquake Engineering, https://doi.ong/10.1007/s10518-017-0288-2 (in-press).

By considering the scale corresponding to $0.5 f_{1}, 2 f_{1}$ and $4.5 f_{1}, E_{\text {scale }(\hat{a})}$ and total wavelet energy, $E_{\text {tot }}$ in Eq. (12) is modified as follows,

in which

$$
D S F=1-\frac{\sum_{i=1}^{3} E_{\text {scale }\left(i \times f_{1}\right)}}{E_{\text {tot }}}
$$

$$
E_{\text {tot }}=\sum_{i=1}^{3} E_{\text {scale }(i \times f)}+E_{\text {scale }\left(0.5 \times f_{1}\right)}+E_{\text {scale }\left(2 \times f_{1}\right)}+E_{\text {scale }\left(4.5 \times f_{1}\right)}
$$

It is generally known that the dynamic response of a frame building is strongly influenced from the ground motion characteristics (i.e., frequency content and/or duration). To consider the impact of ground motion uncertainty on the dynamic response of the examined buildings, Figure 15 illustrates in a semi-log scale the scatter plot of the waveletbased $\mathrm{DSF}_{1}$ versus maximum SDR for the 8-story steel MRF for 10 ground motions. Referring to Figure 15(a), the scatter of SDRs is fairly wide when the original wavelet-based $\mathrm{DSF}_{1}$ is employed. Referring to Figure 15(b), the modified wavelet-based $\mathrm{DSF}_{1}$ reduces the variability of SDRs even at small DSF values. The refined wavelet-based $\mathrm{DSF}_{1}$ is better correlated with the maximum SDR of the 8 -story steel MRF (i.e., $\rho=0.69$ ). Same conclusions hold true for steel MRFs ranging from 2- to 20-stories (Hwang and Lignos 2017) that were also tested but not shown here due to brevity.

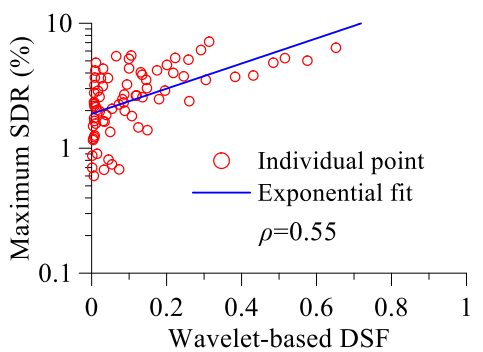

(a) Original $\mathrm{DSF}_{1}$

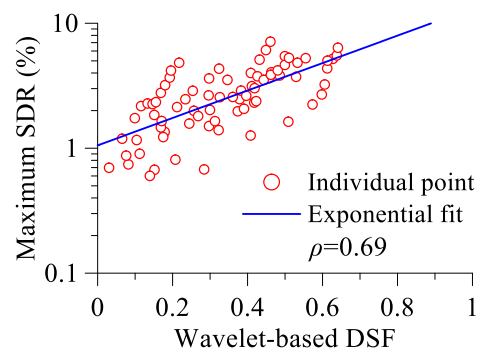

(b) Refined $\mathrm{DSF}_{1}$

Fig. 15 Comparison of wavelet-based DSFs of the 8-story steel MRF.

\section{UTILIZING DAMAGE SENSITIVE FEATURES FOR PERFORMANCE-BASED SEISMIC} ASSESSMENT

In this section, an attempt is made to relate the wavelet-based DSFs discussed and thoroughly evaluated in the previous section with typical story-based EDPs that are used for structural and non-structural damage control (FEMA 2012) such as the peak SDRs, residual SDRs and peak absolute floor accelerations (PFAs). Figure 16 illustrates in a semi$\log$ scale a scatter plot of wavelet-based DSFs versus maximum values of the aforementioned EDPs over the height of all the case studies discussed in Section 3. The wavelet-based DSF $_{1}$ is computed from the absolute acceleration response recorded at the roof of each structure based on Eq. (18). In the same figure, an exponential fit is superimposed as well as the Pearson correlation coefficient $\rho$ of the wavelet-based DSF with respect to the maximum EDP values. From Figure 16, the refined $\mathrm{DSF}_{1}$ is well correlated with the maximum SDRs and residual SDRs and therefore it has the potential to be used as a global damage indicator. Referring to Figure 16, the EDP-DSF relation is exponential. At low seismic intensities that the examined case studies remain elastic; thus, the DSF values are nearly zero (i.e., DSF < 0.1). However, while the ground motion intensities increase the corresponding EDPs also increase as expected. This is also indicated by a smooth increase in DSF values. Once the steel frame buildings approach the point that they lose their lateral load resistance (i.e., dynamic instability occurs) then the DSF values rapidly approach unity. Figure 16(b) suggests that the wavelet-based DSFs may be utilized as global indicators for the potential building demolition in the aftermath of an earthquake. This decision is normally related to the expected residual SDRs (FEMA 2012). To further expand these findings, Figure 17 illustrates the same semi-log scale scatter plot for the 8 -story steel MRF. The available data shown in this figure were produced by rigorous NRHAs with a set of 40 ground motions as discussed earlier. 
This peer-reviewed published paper appears as: Hwang, S-H., Lignos, D.G. (2017). “Assessment of Structural Damage Detection Methods for Steel Structures Using Full-Scale Experimental Data and Nonlinear Analysis, Bulletin of Earthquake Engineering, https://doi.ong/10.1007/s10518-017-0288-2 (in-press).

600

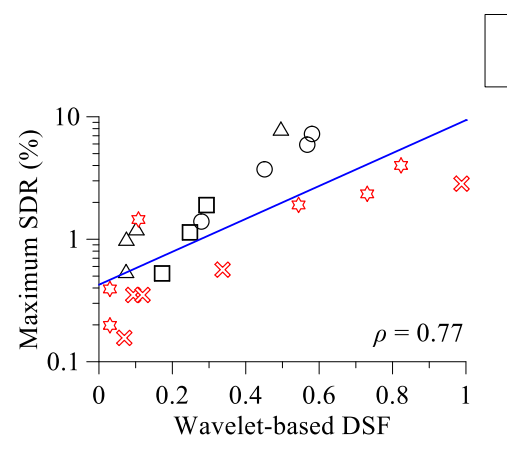

(a) Maximum SDR

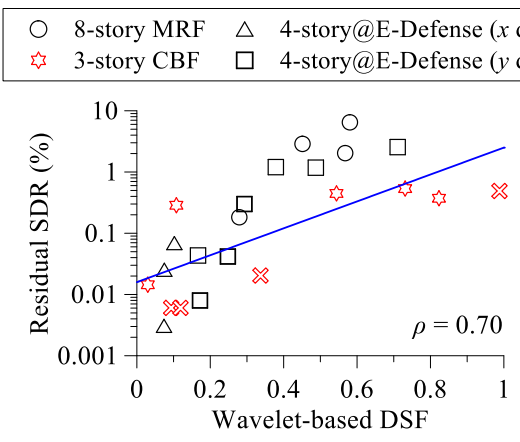

(b) Residual SDR

Fig. 16 Scatter plots of wavelet-based DSF determined from the roof versus story-based peak EDPs for all the case studies examined.

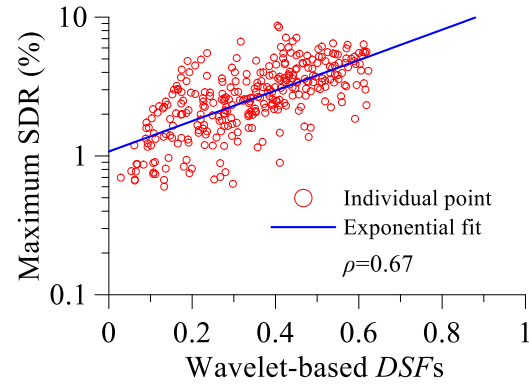

(a)

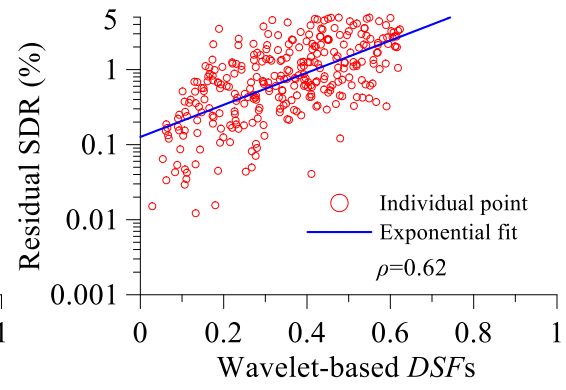

(b)

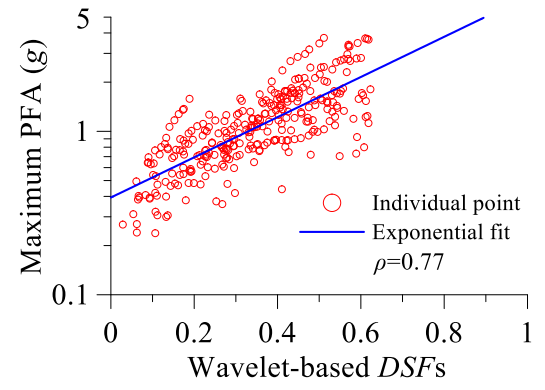

(c)

Fig. 17 Scatter plots of wavelet-based DSF versus maximum EDPs for the 8-story MRF.

\section{SUMMARY AND CONCLUSIONS}

This paper evaluated a number of nonmodel-based approaches that are currently employed in structural health monitoring (SHM) to infer the structural damage state in the aftermath of an earthquake. In particular, three widely used system identification algorithms were considered including the frequency domain decomposition, the autoregressive with exogenous term (ARX) method and the subspace system identification (N4SID) approach to quantify the changes in the dynamic properties of a building (i.e., natural frequency, damping ratio and mode shapes) due to structural damage. The potential of such properties to be used as damage indicators was examined. Waveletbased damage-sensitive features (DSFs) were also considered. The assessment of the aforementioned techniques was conducted on the basis of landmark test data from full-scale shake table experiments complemented with nonlinear simulations of steel moment-resisting frames (MRFs) and concentrically braced frames (CBFs). The findings were grouped per lateral load-resisting system.

The results suggest that the observed changes in natural frequencies do not differ by more than $20 \%$ even at ultimate limit states associated with structural collapse in capacity-designed steel MRFs in which structural damage is mostly attributed to flexural yielding and local buckling. These are deemed to be ductile failure modes according to modern seismic code provisions around the world. This finding does not seem to be influenced by the type of collapse mechanism observed in steel MRFs (i.e., weak-story versus full-frame). Contrary to steel MRFs, large shifts in natural frequency are observed in code-compliant steel CBFs in which the damage progression is typically associated with a rapid loss of lateral stiffness due to steel brace buckling and fracture.

The equivalent damping ratio typically increases while the structural damage progresses with increasing ground motion intensity. This is mainly attributed to the increase of hysteretic damping due to flexural yielding and brace 
This peer-reviewed published paper appears as: Hwang, S-H., Lignos, D.G. (2017). “Assessment of Structural Damage Detection Methods for Steel Structures Using Full-Scale Experimental Data and Nonlinear Analysis, Bulletin of Earthquake Engineering, https://doi.ong/10.1007/s10518-017-0288-2 (in-press). buckling of structural components in steel MRFs and CBFs, respectively. In this case, the choice of the system identification algorithm is important. It was found that the N4SID method provides more stable results compared to the FDD method. Therefore, the equivalent damping ratios may provide insights for the damage progression of steel frame buildings if friction damping is fairly minimal. It was found that the equivalent damping ratio seems to be insensitive to ultimate damage states associated with steel brace fracture.

Although the steel MRFs were subjected to low-probability of occurrence ground motions that triggered structural collapse, the mode shape changes based on the modal assurance criterion (MAC) did not seem to be significant. This criterion seems to infer reasonably well the ultimate damage states associated with brace fracture of steel CBFs in which a sudden lateral stiffness loss is to be expected.

Wavelet-based DSFs seem to be promising when they are employed as global damage indicators regardless of the lateral load-resisting system of the respective steel frame building. A refined wavelet-based DSF is proposed that captures reasonably well the contribution of higher mode effects in cases that are deemed to be important. Through a number of illustrative examples, it was confirmed that wavelet based DSFs are well correlated with story-based engineering demand parameters of both steel MRFs and CBFs at a given seismic intensity of interest.

\section{Acknowledgements}

This study is based on work supported by the Fonds de recherché du Québec - Nature et technologies, Projet de Recherché en Equipe, Award No. FQRNT 2013-PR-167747. Financial support was also provided by the Swiss Federal Institute of Technology in Lausanne (EPFL). The financial support is gratefully acknowledged. The authors also thank Dr. Ahmed Elkady for sharing his nonlinear building model of the 8-story steel moment-resisting frame. The authors also thank Dr. Tsuyoshi Hikino and Prof. Masayoshi Nakashima for providing the experimental data of the two structures tested at the E-Defense facility administered by the National Research Institute for Earth Science and Earthquake Mitigation (NIED). Any opinions, findings, and conclusions or recommendations expressed in this paper are those of the authors and do not necessarily reflect the views of the sponsors.

\section{References}

Aguirre DA, Gaviria CA, Montejo LA (2013) Wavelet-based damage detection in reinforced concrete structures subjected to seismic excitations. Journal of Earthquake Engineering 17(8):1103-1125

AIJ (2007) Structural Steelwork Specification for Building Construction. Japanese Architectural Standard Specification (JASS) 6, Architecture Institute of Japan, Tokyo, Japan

AISC (2010a) Prequalified connections for special and intermediate steel moment frames for seismic applications. ANSI/AISC 358-10, American Institute of Steel Construction, Chicago, IL

AISC (2010b) Seismic provisions for structural steel buildings. ANSI/AISC 341-10, American Institute of Steel Construction, Chicago, IL

Allemang RJ, Brown DL (1982) Correlation coefficient for modal vector analysis. In: Proceedings of the 1st International Modal Analysis Conference (IMAC), Orlando, FL, pp 110-116

ASCE (2010) Minimum design loads for buildings and other structures. ASCE/SEI 7-10, American Society of Civil Engineers, Reston, VA

Balafas K, Kiremidjian AS (2015) Development and validation of a novel earthquake damage estimation scheme based on the continuous wavelet transform of input and output acceleration measurements. Earthquake Engineering \& Structural Dynamics 44(4):501-522

Bažant ZP, Cedolin L (1991) Stability of structures: elastic, inelastic, fracture and damage theories. Oxford University Press, Inc., New York

Bernal D, Gunes B (2004) Flexibility based approach for damage characterization: Benchmark application. Journal of Engineering Mechanics 130(1):61-70 
This peer-reviewed published paper appears as: Hwang, S-H., Lignos, D.G. (2017). “Assessment of Structural Damage Detection Methods for Steel Structures Using Full-Scale Experimental Data and Nonlinear Analysis, Bulletin of Earthquake Engineering, https://doi.ong/10.1007/s10518-017-0288-2 (in-press).

671 Bradley C, Sizemore J, Nelson J, Tremblay R, Hines EM, Fahnestock LA (2014) Large-scale testing of low-ductility, 672 concentrically-braced frames. In: Proceedings of Structures Congress 2014, Boston, MA, pp 2417-2428

673 Brincker R, Zhang L, Andersen P (2001) Modal identification of output-only systems using frequency domain 674 decomposition. Smart materials and structures 10(3):441-445

675 Bruneau M, Chang SE, Eguchi RT, Lee GC, O'Rourke TD, Reinhorn AM, Shinozuka M, Tierney K, Wallace WA, 676 von Winterfeldt D (2003) A framework to quantitatively assess and enhance the seismic resilience of communities. 677 Earthquake Spectra 19(4):733-752

678 Caicedo JM, Dyke SJ, Johnson EA (2004) Natural excitation technique and eigensystem realization algorithm for phase I of the IASC-ASCE benchmark problem: Simulated data. Journal of Engineering Mechanics 130(1):49-60

Chang M, Pakzad SN (2013) Modified natural excitation technique for stochastic modal identification. Journal of Structural Engineering 139(10):1753-1762

Chang M, Pakzad SN (2014a) Observer Kalman filter identification for output-only systems using interactive structural modal identification toolsuite. Journal of Bridge Engineering 19(5):04014002-1

Chang M, Pakzad SN (2014b) Optimal sensor placement for modal identification of bridge systems considering number of sensing nodes. Journal of Bridge Engineering 19(6):04014019-1

Cruz PJS, Salgado R (2009) Performance of vibration-based damage detection methods in bridges. Computer-Aided Civil and Infrastructure Engineering 24(1):62-79

Elkady A, Lignos DG (2014) Modeling of the composite action in fully restrained beam-to-column connections: implications in the seismic design and collapse capacity of steel special moment frames. Earthquake Engineering \&

Elkady A, Lignos DG (2015) Effect of gravity framing on the overstrength and collapse capacity of steel frame buildings with perimeter special moment frames. Earthquake Engineering \& Structural Dynamics 44(8):1289-1307

FEMA (2012) Seismic performance assessment of buildings, volume 1-methodology. Tech. Rep. No. FEMA P-58-1, prepared by the Applied Technology Council for the Federal Emergency Management Agency, Washington, DC Diego, La Jolla, CA

Han SW, Kim WT, Foutch DA (22007) Seismic behavior of HSS bracing members according to width-thickness ratio under symmetric cyclic loading. Journal of Structural Engineering 133(2):264-273

Hera A, Hou Z (2004) Application of wavelet approach for ASCE structural health monitoring benchmark studies.

Hwang SH, Lignos DG (2017) Proposed methodology for earthquake-induced loss assessment of instrumented steel frame buildings: building-specific and city-scale approaches. In: Proceedings of the 6th ECCOMAS Thematic Conference on Computational Methods in Structural Dynamics and Earthquake Engineering (COMPDYN 2017), Rhodes Island, Greece

Ibarra LF, Medina RA, Krawinkler H (2005) Hysteretic models that incorporate strength and stiffness deterioration. Earthquake Engineering \& Structural Dynamics 34(12):1489-1511

Ikeda Y (2016) Verification of system identification utilizing shaking table tests of a full-scale 4-story steel building. Earthquake Engineering \& Structural Dynamics 45(4):543-562

Ji X, Fenves GL, Kajiwara K, Nakashima M (2011) Seismic damage detection of a full-scale shaking table test structure. Journal of Structural Engineering 137(1):14-21

Johnson EA, Lam HF, Katafygiotis LS, Beck JL (2004) Phase I IASC-ASCE structural health monitoring benchmark problem using simulated data. Journal of Engineering Mechanics 130(1):3-15

Karamanci E, Lignos DG (2014) Computational approach for collapse assessment of concentrically braced frames in seismic regions. Journal of Structural Engineering 140(8): A4014019-1 
This peer-reviewed published paper appears as: Hwang, S-H., Lignos, D.G. (2017). “Assessment of Structural Damage Detection Methods for Steel Structures Using Full-Scale Experimental Data and Nonlinear Analysis, Bulletin of Earthquake Engineering, https://doi.ong/10.1007/s10518-017-0288-2 (in-press).

716 Kim J, Lynch JP (2012) Subspace system identification of support-excited structures-part I: theory and black-box system identification. Earthquake Engineering \& Structural Dynamics 41(15):2235-2251

Labuz EL, Chang M, Pakzad SN (2010) Local damage detection in beam-column connections using a dense sensor network. In: Proceedings of ASCE Structures Congress 2010, Orlando, FL, pp 3143-3154

Lai JW, Mahin SA (2014) Steel concentrically braced frames using tubular structural sections as bracing members: Design, full-scale testing and numerical simulation. International Journal of Steel Structures 14(1):43-58

Lehman DE, Roeder CW, Herman D, Johnson S, Kotulka B (2008) Improved seismic performance of gusset plate connections. Journal of Structural Engineering 134(6):890-901

Li X, Kurata M, Suzuki A (2017) Decoupling algorithm for evaluating multiple beam damages in steel momentresisting frames. Earthquake Engineering \& Structural Dynamics 46(7): 1045-1064

Lignos DG, Karamanci E (2013a) Drift-based and dual-parameter fragility curves for concentrically braced frames in seismic regions. Journal of Constructional Steel Research 90:209-220

Lignos DG, Karamanci E (2013b) Predictive equations for modeling cyclic buckling and fracture of steel braces. In: Proceedings of the 10th International Conference on Urban Earthquake Engineering (10CUEE), Tokyo, Japan, pp 105107

Lignos DG, Krawinkler H (2011) Deterioration modeling of steel components in support of collapse prediction of steel moment frames under earthquake loading. Journal of Structural Engineering 137(11):1291-1302

Lignos DG, Krawinkler H, Whittaker AS (2011) Prediction and validation of sidesway collapse of two scale models of a 4-story steel moment frame. Earthquake Engineering \& Structural Dynamics 40(7):807-825

Lignos DG, Hikino T, Matsuoka Y, Nakashima M (2013) Collapse assessment of steel moment frames based on EDefense full-scale shake table collapse tests. Journal of Structural Engineering 139(1):120-132

Lignos DG, Krawinkler H, Whittaker AS (2009) Collapse assessment of a 4-story steel moment resisting frame. In: Proceedings of the 2nd ECCOMAS Thematic Conference on Computational Methods in Structural Dynamics and Earthquake Engineering (COMPDYN 2009), Rhodes Island, Greece

Lignos DG, Karamanci E, Martin G (2012) A steel database for modeling post-buckling behavior and fracture of concentrically braced frames under earthquakes. In: Proceedings of the 15th World Conference on Earthquake Engineering (15WCEE), Lisbon, Portugal, p. 4366

Luş, H, Betti R, Yu J, De Angelis M (2004) Investigation of a system identification methodology in the context of the ASCE benchmark problem. Journal of Engineering Mechanics 130(1):71-84

Lynch JP, Farrar CR, Michaels JE (2016) Structural health monitoring: technological advances to practical implementations. Proceedings of the IEEE 104(8):1508-1512

MacRae GA, Clifton GC, Bruneau M, Kanvinde A, Gardiner S (2015) Lessons from steel structures in Christchurch earthquakes. In: Proceedings of the 8th International Conference on Behavior of Steel Structures in Seismic Areas (STESSA), Shanghai, China, pp 1474-1481

Mahin SA (1998) Lessons from damage to steel buildings during the Northridge earthquake. Engineering Structures 20(4-6):261-270

Mallat S (1999) A wavelet tour of signal processing, 2nd edn. Academic press, New York

McKenna FT (1997) Object oriented finite element programming frameworks for analysis, algorithms and parallel computings. PhD thesis, Department of Civil and Environmental Engineering, University of California at Berkeley, Berkeley, CA

Medina RA, Krawinkler H (2003) Seismic demands for nondeteriorating frame structures and their dependence on ground motions. Tech. Rep. No. 144, The John A. Blume Earthquake Engineering Center, Stanford University, Stanford, CA

Moaveni B, He X, Conte JP, Restrepo JI, Panagiotou M (2011) System identification study of a 7-story full-scale building slice tested on the UCSD-NEES shake table. Journal of Structural Engineering 137(6):705-717 
This peer-reviewed published paper appears as: Hwang, S-H., Lignos, D.G. (2017). “Assessment of Structural Damage Detection Methods for Steel Structures Using Full-Scale Experimental Data and Nonlinear Analysis, Bulletin of Earthquake Engineering, https://doi.ong/10.1007/s10518-017-0288-2 (in-press).

761 Morlet J, Arens G, Fourgeau E, Glard D (1982) Wave propagation and sampling theory-part I: Complex signal and 762 scattering in multilayered media. Geophysics 47(2):203-221

763 Nair KK, Kiremidjian AS (2007) Damage diagnosis algorithms for wireless structural health monitoring. Tech. Rep. 764 No. 165, The John A. Blume Earthquake Engineering Center, Stanford University, Stanford, CA.

Nair KK, Kiremidjian AS (2009) Derivation of a damage sensitive feature using the Haar wavelet transform. Journal of Applied Mechanics 76(6): 061015-1

Nakashima M, Ji X, Lignos DG (2010) Roles of large-scale shaking table testing for verification of advanced technologies on structural control and monitoring. In: Proceedings of the 5th World Conference on Structural Control andMonitoring (5WCSCM), Tokyo, Japan, p 002

NIST (2010) Evaluation of the FEMA P-695 methodology for quantification of building seismic performance factors. Tech. Rep. No. NIST GCR 10-917-8, prepared by the NEHRP Consultants Joint Venture for the National Institute of Standards and Technology, Gaithersburg, MD

Noh HY, Nair KK, Lignos DG, Kiremidjian AS (2011) Use of wavelet-based damage-sensitive features for structural damage diagnosis using strong motion data. Journal of Structural Engineering 137(10):1215-1228

Noh HY, Lignos DG, Nair KK, Kiremidjian AS (2012) Development of fragility functions as a damage classification/prediction method for steel moment-resisting frames using a wavelet-based damage sensitive feature. Earthquake Engineering \& Structural Dynamics 41(4):681-696

Okazaki T, Lignos DG, Hikino T, Kajiwara K (2013a) Dynamic response of a chevron concentrically braced frame. Journal of Structural Engineering 139(4):515-525

Okazaki T, Lignos DG, Midorikawa M, Ricles JM, Love J (2013b) Damage to steel buildings observed after the 2011 TohokuOki earthquake. Earthquake Spectra 29(S1):S219-S243

Overschee PV, Moor BD (1994) N4SID: Subspace algorithms for the identification of combined deterministicstochastic systems. Automatica 30(1):75-93

Ozcelik O, Luco JE, Conte JP, Trombetti TL, Restrepo JI (2008) Experimental characterization, modeling and identification of the NEES-UCSD shake table mechanical system. Earthquake Engineering \& Structural Dynamics 37(2):243-264

Pakzad SN, Fenves GL (2009) Statistical analysis of vibration modes of a suspension bridge using spatially dense wireless sensor network. Journal of Structural Engineering 135(7):863-872

PEER/ATC (2010) Modeling and acceptance criteria for seismic design and analysis of tall buildings. Tech. Rep. No. PEER/ATC 72-1, prepared by Applied Technology Council for Pacific Earthquake Engineering Center, Redwood City, CA

Peeters B, Ventura CE (2003) Comparative study of modal analysis techniques for bridge dynamic characteristics. Mechanical Systems and Signal Processing 17(5):965-988

Rodgers JE, Çelebi M (2006) Seismic response and damage detection analyses of an instrumented steel momentframed building. Journal of Structural Engineering 132(10):1543-1552

Saito T, Beck JL (2010) Bayesian model selection for ARX models and its application to structural health monitoring. Earthquake Engineering \& Structural Dynamics 39(15):1737-1759

Sen AD, Roeder CW, Berman JW, Lehman DE, Li CH, Wu AC, Tsai KC (2016) Experimental investigation of chevron concentrically braced frames with yielding beams. Journal of Structural Engineering 142(12): 04016123-1

Shih C, Tsuei Y, Allemang R, Brown D (1988) Complex mode indication function and its applications to spatial domain parameter estimation. Mechanical Systems and Signal Processing 2(4):367-377

802 Solís M, Algaba M, Galvín P (2013) Continuous wavelet analysis of mode shapes differences for damage detection. 803 Mechanical Systems and Signal Processing 40:645-666

804 Suita K, Yamada S, Tada M, Kasai K, Matsuoka Y, Shimada Y (2008) Collapse experiment of 4-story steel moment 805 frame: part 2 detail of collapse behavior. In: Proceedings of the 14th World Conference on Earthquake Engineering 806 (14WCEE), Beijing, China, p 011 
This peer-reviewed published paper appears as: Hwang, S-H., Lignos, D.G. (2017). “Assessment of Structural Damage Detection Methods for Steel Structures Using Full-Scale Experimental Data and Nonlinear Analysis, Bulletin of Earthquake Engineering, https://doi.ong/10.1007/s10518-017-0288-2 (in-press).

807 Tremblay R (2002) Inelastic seismic response of steel bracing members. Journal of Constructional Steel Research $808 \quad 58(5-8): 665-701$

809 Tremblay R, Filiatrault A, Bruneau M, Nakashima M, Prion HGL, DeVall R (1996) Seismic design of steel buildings: 810 lessons from the 1995 Hyogo-ken Nanbu earthquake. Canadian Journal of Civil Engineering 23(3):727-756

811 Uang CM, Yu QS, Sadre A, Bonowitz D, Youssef N, Vinkler J (1997) Seismic response of an instrumented 13-story 812 steel frame building damaged in the 1994 Northridge earthquake. Earthquake Spectra 13(1):131-149

813 Uriz P (2005) Towards earthquake resistant design of concentrically braced steel structures. PhD thesis, Department 814 of Civil and Environmental Engineering, University of California at Berkeley, Berkeley, CA

815 Yuen KV, Au SK, Beck JL (2004) Two-stage structural health monitoring approach for phase I benchmark studies. 816 Journal of Engineering Mechanics 130(1):16-33 